\title{
Gobierno de los jueces. La Corte Constitucional de Colombia y la "segunda reelección presidencial"1
}

Government of judges. The Constitutional Court of Colombia and the "second presidential reelection"

Governo dos juízes. O Tribunal Constitucional da Colômbia e a "segunda reeleição presidencial"

Gouvernement des juges. La Cour constitutionnelle de Colombie et la "deuxième réélection présidentielle"

\section{Raúl Gustavo Ferreyra ${ }^{2}$ Universidad de Buenos Aires}

Revista Derechos en Acción / ISSN 2525-1678 / e-ISSN 2525-1686

Año 4/Nº 10 Verano 2018/2019 (21 diciembre a 21 marzo), 23-77

DOl: https://doi.org/10.24215/25251678e245

ORCID: https://orcid.org/0000-0001-5089-8136

Recibido: 17/02/2019

Aprobado: 01/03/2019

Resumen: En el presente trabajo se analiza el "constitucionalismo ciudadano" que inteligentemente comporta una inequívoca elección por el gobierno del Derecho que emana de la Ley fundamental del Estado. Se desarrolla en el sistema jurídico colombiano la relación entre la ciudadanía y el poder judicial en un caso de interpretación de la Constitución Política de Colombia, y se profundiza en la sentencia de su Corte Constitucional que dictó una decisión judicial obturando la segunda reelección presidencial de Álvaro Uribe Vélez, al resolver declarar inexequible en

1 Comunicación presentada al XIV Congreso Iberoamericano de Derecho constitucional, Facultad de Derecho, Universidad de Buenos Aires. 21, 22 y 23 de mayo de 2019. Tema central: "Poder judicial y jurisdicción constitucional". Mesa. Justicia y proceso políticos. Interacción entre la jurisdicción constitucional y legal. Contribución dedicada al doctor Roberto Coronel

2 Abogado. Profesor titular de Derecho constitucional, Facultad de Derecho (FD) de la Universidad de Buenos Aires (UBA). Doctor en Derecho (UBA). Posdoctor en Derecho constitucional, (FD-UBA). Correo electrónico: rgferreyra@derecho.uba.ar 
su totalidad la Ley 1354 de 2009, por siete votos contra dos. Se califica a esta decisión judicial como una de las resoluciones que, en el inventario general, puede ser computada como de las más relevantes que se han pronunciado en la historia de la jurisdicción de la América del Sud. El constitucionalismo ciudadano, un cultivo abnegado de la Ley fundamental, alumbra la factibilidad de una participación determinante e inclusiva de cada ser humano en la búsqueda y afirmación de una ciudadanía plena. La sentencia en análisis significa un verdadero contrapeso, una especie de "gobierno de los jueces" demoledor e injustificado. Ella misma, con afán de constitucionalidad, negó y prohibió el instrumento racional y pacífico de reforma, el sufragio de los ciudadanos que integran el pueblo, único presupuesto ontológico del Derecho constitucional. Contra la emergencia que produjo "la sentencia" se ensaya esta tesis, cuyas proposiciones capitales se construyen y justifican, en todo el recorrido de este estudio, con las propias piezas de la Ley fundamental colombiana de 1991.

Palabras claves: gobierno. Jueces. Constitucionalismo ciudadano. Constitución Política de Colombia. Reelección presidencial

Abstract: In the present work we analyze the "citizen constitutionalism" that intelligently involves an unequivocal election by the government of Law that emanates from the fundamental Law of the State. The relationship between citizens and the judiciary is developed in the Colombian legal system in a case of interpretation of the Political Constitution of Colombia, and deepens in the sentence of its Constitutional Court that issued a judicial decision sealing the second presidential reelection of Alvaro Uribe Vélez, in deciding to declare unconstitutional in its entirety Law 1354 of 2009, by seven votes against two. This judicial decision is qualified as one of the resolutions that, in the general inventory, can be considered as one of the most relevant that has been pronounced in the history of the jurisdiction of South America. Citizen constitutionalism, a selfless cultivation of the fundamental Law, illuminates the feasibility of a decisive and inclusive participation of each human being in the search and affirmation of a full citizenship. The judgment in analysis means a real counterweight, a kind of "government of the judges" devastating and unjustified. She herself, with a desire for constitutionality, denied and banned the rational and peaceful instrument of reform, the suffrage of the citizens that make up the people, the only ontological budget for 
constitutional law. Against the emergency that produced "the sentence" is tested this thesis, whose capital propositions are built and justified, throughout the course of this study, with the own pieces of the Colombian fundamental law of 1991.

Keywords: government. Judges. Citizen constitutionalism. Political Constitution of Colombia. Presidential reelection

Resumo: No presente trabalho é analisado o "constitucionalismo cidadão" que inteligentemente implica uma eleição inequívoca pelo governo de Direito que emana da Lei Fundamental do Estado. Se desenvolve no sistema legal colombiano a relação entre a cidadania e o poder judicial em um caso de interpretação da Constituição Política da Colômbia, e aprofunda na sentença do Tribunal Constitucional que emitiu uma decisão judicial obturando a reeleição presidencial de Alvaro Uribe Vélez, ao decidir declarar inexequível em sua totalidade a Lei 1354 de 2009, por sete votos contra dois. É qualificada esta decisão judicial como uma das resoluções que, no inventário geral, pode ser computada como das mais importantes que pronunciaram na história da jurisdição da América do Sul. 0 constitucionalismo cidadão, uma cultura dedicada a Lei Fundamental, ilumina a viabilidade de uma participação decisiva e inclusiva de cada ser humano na pesquisa e afirmação de uma cidadania plena. A sentença em análise significa um contrapeso real, uma espécie de "governo dos juízes" devastador e injustificado. Ela mesma, com ânsia de constitucionalidade, negou e proibiu o instrumento racional e pacífico de reforma, o sufrágio dos cidadãos que compõem o povo, o único pressuposto ontológico do direito constitucional. Contra a emergência que produziu "a sentença" se ensaia esta tese, cujas proposições fundamentais são construídas e justificadas, em tudo o curso deste estudo, com as próprias peças da lei fundamental colombiana de 1991.

Palavras-chave: governo. Juízes. Constitucionalismo cidadão. Constituição Política da Colômbia. Reeleição Presidencial

Résumé: Dans ce travail, nous analysons le "constitutionnalisme citoyen" que de manière intelligente implique une décision claire à faveur du gouvernement du Droit, résultant de la Loi Fundamental de l'État. Dans le système légal colombien, la relation entre la citoyenneté et le pouvoir judiciaire se développe dans un cas d'interprétation de la Constitution politique du Colombia, qui s'approfondit dans le jugement 
de son Constitutional court qui a dicté une décision judiciaire scellant la deuxième réélection présidentielle d'Álvaro Uribe Velez, en declarant non appliquant la loi 1354 de 2009, par sept voix contre deux. Cet jugement a eté qualifié comme une des résolutions les plus relevantes qui ont été prononcés dans I'histoire de la juridiction d'America du Sud. Le constitutionnalisme citoyen, une culture désintéressée de la loi fondamentale, allume la possibilité d'une participation décisive et inclusive de chaque être humain à la recherche et à l'affirmation d'une citoyenneté pleine. Le jugement en analyse signifie un véritable contrepoids, une sorte de "gouvernement des juges" dévastateur et injustifié. Elle-même, désireuse de constitutionnalité, a nié et interdit l'instrument de réforme rationnelle et pacifique, le suffrage des citoyens qui font le peuple, la seule condition ontologique du droit constitutionnel. Contre l'urgence qui le jugement a produit, on nous répète cette thèse, dont les propositions capitales sont construites et justifiées, tout au long de cette étude, avec les propres pièces de la loi fondamentale colombienne de 1991.

Mot-clés: Gouvernement. Juges. Constitutionnalisme citoyen. Constitution politique de la Colombie. Réélection présidentielle.

\section{Obertura}

El constitucionalismo se nutre de la idea de que la Ley fundamental determina la raíz del Estado y justifica o legitima, hasta cierto punto, el ejercicio de sus poderes siempre atribuidos por competencia específica.

La mancomunidad social, ya sea que haya sido inventada por el ser humano o sea la forma inmediata para acoger su existencia, requiere de procesos de ordenación y control, y puede alcanzar cierto grado de compromiso, siempre imperfecto. Una de las herramientas más fértiles para mancomunar la ciudadanía es el constitucionalismo. Un proceso creado por el hombre que ha de consistir en un cultivo, perenne y preciso, de una Ley fundamental que establezca -como utopía o sin ella- la posible ordenación de la coexistencia en paz. Con otras palabras, dado que la existencia en comunidad se desarrolla por intermedio de 
"consensos" y "conflictos" entre sus ciudadanos, que jamás son definitivos -acaso treguas momentáneas seguidas de compromisos a plazo fijo-, la Constitución fungiría como una forma que puede convertirse en paradigma de idoneidad. Por eso, la Constitución, una singular norma procesal, puede ser comprendida como el tratado de paz más duradero ${ }^{3}$ para enmarcar la dialéctica infinita de la existencia humana.

El Derecho es pura creación política y la Constitución, su expresión máxima, hasta nuevo aviso.

Una vez producido el Derecho constituyente del Estado, se tratará, precisamente, de mantenerlo y desarrollarlo. Legisladores, jueces, legisladores, presidentes, en fin, todos los servidores públicos realizan actos políticos; desde luego, en diferentes órbitas y con definidas y ajustadas competencias. Controlar la constitucionalidad es una tarea obligada para todos los servidores públicos, incluso la ciudadanía, aunque en general la última palabra, con asombrosas cualidades de monólogo, se reserve a la jurisdicción.

Garantizar la constitucionalidad significa instituir "mecanismos" para que la Ley suprema se mantenga como fundamento supremo del orden estatal, al respaldar la estructura jerárquica de éste y consagrar la subordinación del Estado al Derecho de la Constitución. No puede dejar de comprenderse esta necesaria e indiscutida distinción: una tarea es determinar el significado de una regla constitucional, al eliminar o no aplicar la regla inferior en conflicto con ella, y otra es generar la regla Constitucional misma, es decir, producirla. Tal afirmación significa que, por un lado, hay órganos de creación y, por otro, órganos de realización. Por ello, aunque el mantenimiento de las reglas de juego del sistema constitucional es una función de capital importancia para su perduración, por la vía de la interpretación, ello no conlleva la idea de eternidad. En rigor de verdad, cuando se deja de atribuir significados, las posibilidades que quedan no son

3 Bовві0, Norberto: El futuro de la democracia, Buenos Aires, Planeta-Agostini, 1994, p. 171. 
muchas, en especial, cuando se considera, equivocadamente, que "crear" Derecho forma parte de la tarea jurisdiccional. En tales casos, el juez anula o devalúa su función y, en descrédito de la división de poderes, vulnera dicha regla, porque finalmente intenta o pretende constituir el Derecho. Tarea reservada, por cierto, al poder constituyente, originario o derivado, nunca a los jueces.

Los fundamentos constitucionales son Derecho político puro, es decir, pura política conducida por el Derecho de la Constitución. Derecho de la ordenación, desarrollo y mantenimiento del orden jurídico del Estado. No hay más Estado para decidir su constitucionalidad que el organizado propiamente por su Ley fundamental. No hay más funciones de los órganos de los poderes del Estado que las delimitadas en la Constitución en sus respectivas zonas de reserva y concurrentes.

Los límites de la competencia de los servidores públicos, incluidos los jueces de una Corte o Tribunal constitucional, son y serán los "límites del lenguaje" ${ }^{4}$ constituyente del Estado, dado que estos lindes no son un adorno sino los límites indisponibles de su mundo jurídico. La tarea de los jueces de un Tribunal constitucional, que por ejemplo gozare de la competencia para eliminar del orden una regla viciada, consistirá en discernir el contenido del lenguaje constituyente, nunca en engendrarlo ni en proponer sus reglas.

Los servidores públicos tienen por función desarrollar y sostener su sistema normativo. Aunque la Constitución mantiene un ámbito insospechado de cierta indeterminación normativa, esta circunstancia no alienta "ningún poder creativo de los jueces" $"$ ni que su tarea no pueda ser expuesta a un robusto control ciudadano, tan sólido como específico, en los casos en que se compruebe la inconstitucionalidad u otro tipo de diálogo

\footnotetext{
4 Wittgenstein, Ludwig: Tractatus Logico-Philosophicus, Madrid, Revista de Occidente, 1957, p. 153.

5 Maler, Julio: Mientras estés conmigo, Buenos Aires, Ad Hoc, 2017, p. 317.
} 
"viciado" con los poderes constituidos. Ir más allá de los límites de la competencia fijada por la Ley fundamental a cada órgano del poder significa desnaturalizar y desmembrar los límites de la lengua prescriptiva de la Constitución.

La historia de las ideas políticas encuentra una huella repetida. En ella se abren dos caminos: por un lado, el gobierno del Derecho y, por otro, el gobierno de los hombres. En el primer sendero, el Derecho subordina la tarea de los hombres; en el segundo, los hombres subordinan, según su libérrima discrecionalidad, al Derecho. Me dedico, aquí, a examinar un caso en el que la autoridad del Derecho constituyente del Estado quedó sometida a la voluntad de los jueces. Concretamente: la Corte Constitucional de la República de Colombia (en adelante, CCC), por mayoría, pronunció la sentencia C-141/10 (en adelante, "la sentencia"), por cuyo intermedio se resolvió "Declarar inexequible en su totalidad la Ley 1354 de 2009. Por medio de la cual se convoca a un referendo constitucional y se somete a consideración del pueblo un proyecto de reforma constitucional".

En todas las piezas que integran este ensayo, quizá el argumento principal consista en la elección decidida por el gobierno del Derecho, con exclusión fulminante del gobierno de los hombres (en este caso: de los jueces que decidieron por mayoría). Para clamar por dicha primacía de la razón del Derecho, en la que no se encuentra la salvación de la comunidad pero sí una posibilidad para evitar su ruina, a continuación presento una verdadera desmesura en el ejercicio del poder jurisdiccional: "la sentencia". Una muestra de voluntad de los gobernantes que no se subordinan al Derecho constituyente del Estado. "La sentencia" es un pequeño artefacto, pero sobre el que pesa una gravísima anomalía congénita que la convierte y confina para toda su vida. Por eso, la llevo más abajo al "extremo de sus consecuencias", y por su extraordinaria anormalidad, reiterada y multiplicada, permite advertir una sinrazón: el "gobierno de los jueces”... sin diálogo. 


\section{$\S$ II. La presidencia de la República de Colombia a comienzos del siglo $X X I$}

La Constitución Política de Colombia (en adelante: CPC 1991) fue sancionada y publicada en julio de 1991. Desde entonces ha sido reformada en reiteradas oportunidades -aunque Colombia posee y padece un mecanismo de "declaración de inexequibles" de las enmiendas en la sede de la CCC-, sin desvanecer ni devaluar las prescripciones originarias de los principios y las reglas que la nutren y desarrollan en las 380 piezas de su articulado gestado con naturaleza permanente.

La CPC 1991 es una Ley fundamental concebida globalmente, poseedora de innovaciones en materia de organización política, social, económica y cultural, aunque no modificó el sistema de gobierno "fuertemente presidencialista" ${ }^{6}$. Las innovaciones económicas, sociales, políticas y jurídicas se hacen sentir desde el Preámbulo hasta las disposiciones transitorias. En sus más de 27 años de vida ha sido reformada por más de 45 actos legislativos que han diseminado, a su vez, cambios en 100 de sus artículos permanentes o transitorios.

Con la CPC 1991 en la cabecera del orden jurídico, Don Álvaro Uribe Vélez fue elegido el 26/5/2002 como Presidente de la República de Colombia. No se necesitó una segunda vuelta electoral porque obtuvo más de $54 \%$ de los sufragios. Su período presidencial comenzó el $7 / 8 / 2002$ y se extendió hasta el 7/8/2006.

Ante la prohibición expresa para un segundo mandato presidencial, única composición deducible del artículo $197^{7}$ de la CPC 1991, Uribe se dirigió al Congreso de la República. La CPC 1991 fue reformada por intermedio del Acto Legislativo 2 del 2004, que confirió una nueva redacción al artículo 197 de

6 Bushnell, David: Colombia. Una nación a pesar de sí misma. Nuestra historia de los tiempos precolombinos hasta hoy, Bogotá, Planeta, 2003, p. 393.

7 Texto originario del artículo 197 de la CPC 1991. “No podrá ser elegido Presidente de la República el ciudadano que a cualquier título hubiere ejercido la Presidencia". 
la Ley fundamental. Sin embargo, el "astuto" programa de Uribe requería de un eslabón: un pronunciamiento jurisdiccional. La reforma constitucional postulada por Uribe para acceder, por segunda vez, a la presidencia de la República fue acusada ante la CCC. El 19/10/2005 la CCC, por mayoría, bendijo en Derecho a las aspiraciones reeleccionistas del entonces "príncipe republicano". En cuanto a lo que aquí concierne, por intermedio de la sentencia C-1040/05 se declaró "exequible" ("constitucional" fuera de Colombia) el Acto Legislativo 2 de 2004, "Por el cual se reforman algunos artículos de la Constitución Política y se dictan otras disposiciones", en particular, la que habilitó la reelección del presidente en ejercicio, como se ha visto más arriba.

La suerte y la astucia para deducir sus "derechos políticos" acompañaron a Uribe. Quedó habilitado constitucionalmente para un segundo período presidencial. Las elecciones presidenciales de realizaron el 28/5/2006. Uribe superó el $62 \%$ de los sufragios, un caudal abrumador. Es, hasta hoy, la única persona en toda la historia política de Colombia en alcanzar semejante apoyo ciudadano en las urnas. Asumió su segunda presidencia el 7/8/2006 con vencimiento del período determinado constitucionalmente para el 7/8/2010.

Antes de vencer su segundo mandato, Uribe inició una nueva "aventura constituyente". Así, logró que el Congreso de Colombia sancionase la ley $1354^{\circ}$, "Por medio de la cual se convoca a un referendo constitucional y se somete a consideración del pueblo un proyecto de reforma constitucional".

Artículo 1. El inciso $1^{\circ}$ del artículo 197 de la Constitución Política quedará así:

"Quien haya sido elegido a la Presidencia de la República por dos períodos constitucionales, podrá ser elegido únicamente para otro período".

Aprueba usted el anterior inciso.

Sí: ( )

8 Diario Oficial No. 47.466, 8/9/2009. 
No: ( )

Voto en Blanco: ( )

Artículo 2. La presente ley regirá a partir de la fecha de su promulgación.

La CPC 1991, en los incisos 1 y 2 del artículo 241, atribuyó competencia a la Corte Constitucional de Colombia (CCC) para entender en el juicio de constitucionalidad que se discierna "sólo" por vicios distinguibles en el "procedimiento" de formación del cambio constituyente 9 . El artículo 241, además, contiene un parágrafo único y final:

Cuando la Corte encuentre vicios de procedimiento subsanables en la formación del acto sujeto a su control, ordenará devolverlo a la autoridad que lo profirió para que, de ser posible, enmiende el defecto observado. Subsanado el vicio, procederá a decidir sobre la exequibilidad del acto.

La propuesta de referendo que portaba una reforma, con una nueva "norma de habilitación" para un segunda reelección presidencial, se remitió a la CCC, en cumplimiento del artículo 241, inciso $2^{\circ}$ de la CPC 1991. La "sentencia" de la CCC pronunciada el 26/2/2010 terminó para siempre con las intenciones de reelección del presidente Uribe. La ley fue declarada inexequible en su totalidad, por mayoría de jueces y por intermedio de "la sentencia" (C-141-2010), sin "antes" oír la voz propia de los ciudadanos que integran el pueblo, fundamento de la democracia y los actores más relevantes para conservar y reformar la

9 Artículo 241. A la Corte Constitucional se le confía la guarda de la integridad y supremacía de la Constitución, en los estrictos y precisos términos de este artículo. Con tal fin, cumplirá las siguientes funciones:

1. Decidir sobre las demandas de inconstitucionalidad que promuevan los ciudadanos contra los actos reformatorios de la Constitución, cualquiera que sea su origen, sólo por vicios de procedimiento en su formación.

2. Decidir, con anterioridad al pronunciamiento popular, sobre la constitucionalidad de la convocatoria a un referendo o a una Asamblea Constituyente para reformar la Constitución, sólo por vicios de procedimiento en su formación. 
constitución ${ }^{10}$. Esta vez la astucia de Uribe no fue iluminada por la suerte. No logró ser reelecto por segunda vez consecutiva.

"La sentencia" puso fin a las aspiraciones reeleccionistas del presidente que, por entonces, ejercía por segunda vez la magistratura en la República de Colombia, servicio público con vencimiento constitucional para el 7 de agosto de 2010. Sin ingresar en su cotización ni escarbar en su plataforma teórica, en los hechos significó la terminación, por vía jurisdiccional, de un pretendido modelo o tipo de presidencialismo continuo o sempiterno. Por su originalidad, no se conoce en América del Sud una decisión jurisdiccional semejante que singulariza una determinada gobernanza. En efecto, en tal tipo de gobierno, los jueces de la CCC asumen, por mayoría, esta ordenación: "no" a la hipótesis de una segunda reelección. La originalidad de "la sentencia" se justifica porque provocó, en el orden jurídico colombiano, su arraigo y mantención, sin apelar al cambio, y así troncó el desarrollo de un proceso político mucho más que en ciernes: la segunda reelección del presidente en ejercicio. El gobierno, por intermedio de sentencias judiciales, coloca a la autoridad o a la rama judicial en el rol de reguladora eminente de los grandes conflictos comunitarios. La novedad de la decisión también merece ser ponderada en sus justos términos. Apuntar esto no significa que la jurisdicción no decida, en América del Sud, contra las políticas de los ejecutivos que gobiernan cada uno de los Estados.

"La sentencia" instituyó un soliloquio jurisdiccional". Por un lado, dispuso detener jurídicamente al líder político de Colombia que gozaba de mayor poder, pero, por otro, al mismo tiempo, impidió la celebración de una convocatoria popular, precisamente, la voz propia del mensaje indisputable que emerge de todo acto electoral que se desarrolle en democracia. El activismo judicial mostrado, aunque quizá resulte conciliable con el orden jurídico estructurado, es inconciliable con el principio

10 Chaux Donado, Francisco José: Adiós a la constitución: ¿Por qué la Constitución de 1991 ya no le pertenece al pueblo de Colombia?, Bogotá, Temis, 2017, p. 257. 
democrático. La limitación jurisdiccional a la soberanía de los ciudadanos del pueblo, pese a encontrar asiento constitucional, torna ineficaz la palabra del individuo sobre sus propias preferencias políticas; en suma, una renuncia impensable al principio de la libre deliberación y elección democrática. La jurisdicción constitucional, con su papel negador, lejos de constituirse en un poder moderador, se convierte, en el contexto referido y en la práctica ejercida, en un poder obturador, que clausura la expresión de una ciudadanía democrática.

"La sentencia" es una de las más relevantes que se han pronunciado en la historia de la jurisdicción de la América del Sud. La adjetivo como "relevante" con segura convicción, porque "equivocar la palabra es equivocar la cosa"11. Sin adelantar mi juicio, se trata de una sentencia que no se adecua al estatuto teórico planteado en este escrito. ¡Pese a ello, resulta escogida! No hace falta decirlo: en el decisorio jurisdiccional se hace aplicación de la doctrina de la sustitución por inconstitucionalidad. En otras palabras: una doctrina colombiana que alcanzaría para censurar, jurisdiccionalmente, el procedimiento y hasta el contenido de una reforma constitucional.

\section{III. "Naturalmente, la sentencia"12}

\section{III.A. Descripción}

Con fecha 26 de febrero de 2010, la Sala Plena de la CCC colombiana dictó la sentencia C-141/10. En una decisión dividida,

\footnotetext{
11 SARTORI, Giovanni: La carrera hacia ninguna parte. Diez lecciones sobre nuestra sociedad en peligro, Buenos Aires, Taurus, 2016, p. 47.

12 "La sentencia", en esta contribución, no cumple, estrictamente, una función como ironía intertextual o elemento metanarrativo. En 1980, Umberto Eco publicó El nombre de la rosa. El encabezado de la página inicial dice "Naturalmente, un manuscrito". En el comienzo de la obra, Eco, narra cómo fue a parar a sus manos un antiguo texto medieval, un manuscrito del siglo xiv. V. Eco, Umberto: El nombre de la rosa, Buenos Aires, Sudamericana, 2017, pp. 7 y 9 , respectivamente. Sin embargo, "la sentencia", aunque nunca fue ni será un manuscrito, cumple, robustamente, el rol de una afirmación histórica que desencadena e influencia la totalidad de los razonamientos. "La sentencia" constituye un hecho memorable e indisputado
} 
la Corte resolvió "Declarar inexequible en su totalidad la Ley 1354 de 2009", por siete votos contra dos. Puntualmente, la mayoría de siete votos en la "cuestión resolutiva" mencionada en el párrafo anterior se conformó con un voto principal que fue suscripto por cuatro magistrados: Juan Carlos Henao Pérez, Gabriel Eduardo Mendoza Martelo, Jorge Iván Palacio Palacio y Luis Ernesto Vargas Silva, y la concurrencia de otros tres magistrados con aclaraciones en sus votos respectivos: María Victoria Calle Correa, Nilson Elías Pinilla Pinilla y Humberto Antonio Sierra Porto. Por su parte, la minoría se integró con dos magistrados que disintieron mediante el salvamento de sus votos: Mauricio González Cuervo y Jorge Ignacio Pretelt Chaljub.

Con tal precisión, seguidamente, ofrezco un panorama sobre los aspectos centrales de la decisión de la mayoría en la sentencia C-141/10 y de su disidencia. Advierto que, a los fines expositivos, llamo "mayoría" al bloque discursivo integrado por Juan Carlos Henao Pérez, Gabriel Eduardo Mendoza Martelo, Jorge Iván Palacio Palacio y Luis Ernesto Vargas Silva. No desconozco que María Victoria Calle Correa, Nilson Elías Pinilla Pinilla y Humberto Antonio Sierra Porto "aclararon su voto" y concurrieron con los cuatro jueces recién citados en el punto resolutivo, pero el más nutrido bloque doctrinario se encuentra integrado por los cuatro jueces aludidos en primer lugar, quienes aunaron esfuerzos para ofrecen un solo discurso. Además, la aclaración de voto de la magistrada Calle Correa no fue publicada. Por iguales razones, apodo "minoría" a la disidencia ofrecida por Mauricio González Cuervo, en la inteligencia de que la disidencia de Pretelt Chaljub fue anunciada y no publicada.

En este punto, deseo aclarar que asumo la responsabilidad de analizar los hechos sin haberlos vivido intensamente en la

de la realidad objetiva. Su existencia es indisimulable y, en cierto sentido, en esta obra, constituye su parición. Así, pues, se genera el presente texto, en cuyo ámbito el lector ideal que nace por la propia obra aceptará que se redacte, sin ironías ni referencias más allá de la propia narración, la siguiente escritura: "Naturalmente, la sentencia". 
comunidad colombiana y, por consiguiente, de haber elaborado una cotización peculiar de su trama argumental. Además, la atmósfera del relato, en especial su presentación y numeración, ha sido escogida con total libertad y con una facultad que sólo busca amenizar la lectura de "la sentencia". Para juzgar la probidad, bastará echar una mirada a la síntesis ${ }^{13}$ que ofrezco, en la que he intentado mantener el vocabulario original hasta donde resultaba razonablemente posible y justificado.

\section{III.A.1. Los argumentos de la decisión "mayoritaria”}

A los fines del presente análisis, las consideraciones y los fundamentos desarrollados por la mayoría se agrupan en tres fragmentos: $a$ ) la dinámica del poder constituyente y los alcances del control de constitucionalidad; $b$ ) el significado de la democracia y el respeto de las reglas procedimentales; y c) la sustitución de la Constitución y la segunda reelección presidencial.

a) La dinámica del poder constituyente y los alcances del control de constitucionalidad:

1. El poder constituyente originario o fundacional es un poder político e ilimitado, que se encuentra exento del control jurisdiccional. En cambio, el poder constituyente derivado

13 En el trabajo de resumir los fundamentos de "la sentencia", he procurado ser fiel a sus palabras, que en ocasiones a su vez corresponden a citas ajenas de autoridad. Para facilitar la legibilidad de este texto, decido colocarlo en un formato de cita extensa, aunque desde luego haya modificado su orden, e incorporado algunas reformulaciones y también supresiones considerables. El original de "la sentencia" se encuentra disponible en http://www.corteconstitucional.gov.co/relatoria/2010/c-141-10.htm consultado por última vez el 28/11/2018.

"La sentencia" contiene alrededor de 200.000 palabras. Comparativamente, la extensión de su textura posee un 40\% más de palabras que Cien años de soledad y un $40 \%$ menos que Don Quijote de la Mancha. Repárese, además, en el hecho de que no hay Constitución vigente en el mundo que supere, con hidalga claridad y eficacia normativa, las 100.000 palabras. En tierra firme y años después de la elaboración de "la sentencia", sobreviene una inquietud: ¿se tratará de un acto jurisdiccional pensado para la lectura crítica, edificante y comprensiva en el ágora ciudadano? En dicha proliferación de letras, los magistrados hicieron mérito de múltiples cuestiones, tanto formales como sustanciales, por lo que su exposición, para no abrumar al lector, se ha ceñido sobre los aspectos que se juzgan más relevantes. 
es un poder jurídico y limitado, que se halla sometido al control jurisdiccional.

2. Una vez dictada una Constitución por el pueblo, éste mismo debe actuar dentro del marco constitucional que se ha dado. El artículo $3^{\circ}$ de la Constitución, según el cual "[l]a soberanía reside en el pueblo, del cual emana el poder público. El pueblo la ejerce en forma directa o por medio de sus representantes, en los términos que la Constitución establece", implica que el pueblo, a pesar de ser el depositario de la soberanía, cuando ejerce el poder de reforma constitucional también debe actuar dentro del marco procedimental y de competencia fijado por la propia Constitución.

3. El art. 241, inciso 2, de la Constitución, en cuanto prescribe que la Corte debe "[d]ecidir, con anterioridad al pronunciamiento popular, sobre la constitucionalidad de la convocatoria a un referendo o a una Asamblea Constituyente para reformar la Constitución, sólo por vicios de procedimiento en su formación", no implica que el control solamente alcance a los límites formales derivados de las reglas procedimentales establecidas por la Constitución y por las normas legales que regulan la materia, sino que se extiende al examen del texto de la ley de convocatoria a referendo para preservar la libertad de los votantes, como así también a los límites materiales que se derivan de la propia competencia en cuestión, que es reformar la Constitución, pero no derogarla, subvertirla o sustituirla en su integridad.

b) El significado de la democracia y el respeto de las reglas procedimentales:

1. La democracia constituye uno de los elementos estructurales del diseño estatal adoptado por la Constitución.

2. En cuanto valor y principio constitucional, la democracia irradia todo el ordenamiento jurídico, de manera tal que condiciona la conformación de los órganos, las funciones y los procedimientos dentro del Estado, para que éstos se 
articulen de forma coherente con los contenidos propios del principio democrático; pero, igualmente, ha de servir como elemento hermenéutico en la comprensión del ordenamiento constitucional e infraconstitucional, de manera que el sentido que se extraiga de las disposiciones concretas no sea contrario a sus postulados.

c) La sustitución de la Constitución y la segunda reelección presidencial:

1. En relación con la sustitución de la Constitución, la "mayoría" de la Corte colombiana reseñó los siguientes criterios: a) El poder de reforma definido por la Constitución está sujeto a límites competenciales; b) En virtud de esos límites competenciales el poder de reforma puede reformar la Constitución, pero no puede sustituirla por otra integralmente distinta u opuesta; c) Para establecer si una determinada reforma a la Constitución es, en realidad, una sustitución de la misma, es preciso tener en cuenta los principios y valores del ordenamiento constitucional que le dan su identidad; d) La Constitución no contiene cláusulas pétreas ni principios intangibles, por consiguiente, todos sus preceptos son susceptibles de reforma por el procedimiento previsto para ello; e) El poder de reforma no puede, sin embargo, derogar, subvertir o sustituir en su integridad la Constitución; y f) Sólo el constituyente primario tendría la posibilidad de producir una tal sustitución.

2. La sustitución implica la franca oposición entre lo nuevo y lo anterior, en la medida en que, so pretexto de la reforma, la Constitución es transformada en otra completamente distinta que, por ejemplo, sirva de base a una forma de organización política opuesta, como cuando se cambia la república por la monarquía, la democracia por la dictadura o el Estado de Derecho por el totalitarismo.

3. Esa sustitución puede ser total, cuando la Constitución como un todo es remplazada por otra; o parcial, cuando un 
eje definitorio de la identidad de la Constitución es reemplazado por otro opuesto o integralmente diferente.

4. De tornarse efectiva la segunda reelección, el tercer período del Presidente desconocería la regla de alternación en el ejercicio del poder político, preservaría por un lapso prolongado las tendencias ideológicas propugnadas por el gobierno, así como los equipos encargados de desarrollar las políticas y propiciaría la continuidad de la mayoría dominante, con notable retraso de la renovación, fuera de lo cual la posibilidad de designar, postular e influir en la composición de otros órganos públicos destruiría la coordinación constitucional de los distintos períodos y tendría por resultado el acrecentamiento del poder presidencial y la pérdida de eficacia de los controles sobre la actuación del Presidente.

5. Por lo tanto, una segunda reelección presidencial sustituye ejes estructurales de la Constitución Política y, por lo tanto, la Ley $\mathrm{n}^{\circ} 1354$ de 2009 que busca hacer posible una reforma constitucional que la instituya vulnera la Constitución y debe ser declarada inconstitucional.

\section{III.A.2. Los contraargumentos de la opinión "minoritaria"}

La minoría, según se adelanta más atrás de conformidad con los fundamentos expresados por el juez M. González Cuervo, rebate las razones de la "mayoría" y cuestiona, esencialmente, la legitimidad del tipo y alcance del control de constitucionalidad desplegado por la Corte.

1. La teoría de la sustitución de la Constitución implica la creación de una especie de vicio mixto -ubicado entre los de trámite y los materiales- relativo a la "competencia" como presupuesto ineludible del procedimiento, que lleva a expandir el espectro de control de la Corte.

2. Sin embargo, con el surgimiento de la categoría de vicios de competencia, la Corte desconoce y desborda los límites de su propia competencia, al mutar el control del procedimiento y emprender el control material de las leyes 
convocatorias al referendo y los actos reformatorios de la Constitución.

3. El control competencial no sólo es extraño a la labor de la Corte, sino también al Título XIII de la Constitución, en el que no se hace ninguna alusión a la existencia de límites competenciales a la potestad reformatoria de ninguno de los tres estamentos legitimados para modificar la norma fundamental.

4. No es válido que la Corte decida inmiscuirse en el contenido material de las leyes convocatorias a referendo, con el supuesto fin de asegurar el cumplimiento de "ejes definitorios" de la Constitución, pues no existe fundamento constitucional alguno para hacerlo.

5. Es fácil identificar cómo, en el juicio de sustitución de la Constitución, el análisis de la Corte no se sustenta en criterios normativos, objetivos y verificables, sino que recurre a la figura de los "ejes definitorios", que están librados en su determinación al subjetivismo del juez, y que petrifican la Constitución impidiendo la reforma democrática y soberana impulsada por el pueblo, desconociendo con ello el principio democrático, la separación de poderes y la soberanía popular que pretendían defenderse.

6. El juicio de sustitución emprendido por la Corte sólo difiere de un juicio material, en el nombre que se le dio al método, pues en la práctica lo que se hace es desconocer el hecho de que la Corte sólo puede ejercer su control por vicios de forma, con lo cual la teoría de la sustitución no es más que una manera de burlar los límites de la competencia de la Corte delineados en la Constitución.

7. Lo que se revela en el juicio de sustitución de la Constitución es la aplicación más subjetiva posible de los dispositivos Constitucionales, y la realización velada de un control material que, para rematar, implica la imposición de una visión aristocrática del derecho por encima de una visión democrática emanada del pueblo soberano. 
8. El juicio de sustitución de la Constitución genera dificultades para hacer predecible el ejercicio de la Corte respecto del control de los actos reformatorios de la Constitución, pues el parámetro de control es indeterminable con anterioridad al ejercicio del poder jurisdiccional de la Corte, por la simple razón de que los supuestos límites al poder de reforma, que son el parámetro para justiciar la misma, no están explícitos en el texto constitucional.

9. La teoría de la sustitución de la Constitución, al ser aplicada en un momento previo al cambio constitucional, produce el efecto de evitar que a través de los cauces democráticos se escoja por el pueblo soberano qué debe y qué no debe hacer parte de la norma fundamental, prefiriéndose la aplicación de un control de constitucionalidad que sustituye al pueblo por el criterio de un estamento que carece por completo de representatividad democrática.

10. El referendo se presenta entonces en pie de igualdad, o incluso superioridad en términos de legitimación para establecer un cambio constitucional, pues es el mismo pueblo soberano el que implementa el cambio, y no un representante en el marco de una Asamblea, que por más definida su competencia, periodo y composición, no es directamente el pueblo, sino uno de sus representantes.

\section{Tesis y estrategia argumentativa}

Ya he señalado que "la sentencia" es una de las resoluciones que, en el inventario general, puede ser computada como de las más relevantes que se han pronunciado en la historia de la jurisdicción de la América del Sud. En efecto, la acción total desplegada por el presidente "no fue iluminada por la suerte" y no logró su segunda reelección. También he afirmado que "la sentencia”, por su extraordinaria anormalidad, reiterada y multiplicada, permite advertir el verdadero desatino sin fundamento en la razón y la angustia institucional que debería provocar el gobierno de los jueces, sobre todo -repito- si se la lleva al punto final de sus 
consecuencias institucionales. "La sentencia" es una muestra de un gobierno de los jueces. Su crítica razonada permite inferir el problema sin solución que se exhibe cuando la Constitución queda, exclusivamente, como un artefacto bajo el poder ecuménico del órgano jurisdiccional o de sus servidores, los jueces, quienes la podrían moldear de acuerdo con sus propias verdades eternas.

Frente a "la sentencia" planteo cinco proposiciones capitales:

(i) La regulación, en la propia lengua de la Constitución, del acuse de inconstitucionalidad formal del proceso detallado respecto del cambio de la ley fundamental y la determinación de la autoridad que deberá resolver el conflicto jamás debería significar una solución cuyos rasgos impliquen la inestabilidad de la fuente de poder ciudadano, su inferioridad o, peor aún, su letal descuido o abandono.

(ii) Constituir a la autoridad jurisdiccional en árbitro supremo de la política comunitaria impediría la liberación horizontal de la palabra pública de los ciudadanos.

(iii) A su vez, queda sin diferencias la distinción entre poder constituyente y poderes constituidos. Esta solución extraordinaria se sitúa fuera de la autoridad de la Constitución y de cualquier argumentación razonable, porque se admitiría una "contrarreforma" por vía jurisdiccional al manifestarse un ejercicio de poder constituyente derivado, ciertamente, no electo por el pueblo para cumplir tal alteración.

(iv) Antes que pensar en las limitaciones al poder jurídico ciudadano para generar reglas jurídicas de la más alta estirpe, ¿no correspondería limitar el poder de los jueces?

(v) ¿La CPC 1991 ha confiado a los jueces de la CCC o al Congreso el deber de determinar la naturaleza, la oportunidad y el contenido de las enmiendas constitucionales? 
Para fortalecer la capacidad explicativa de la tesis principal plantada, he dispuesto la fragmentación del discurso que la justifica. Sin embargo, la tesis se trata de una construcción severamente codificada, razón por la cual cada uno de los fragmentos no deben empalidecer ni hacer temer sobre el énfasis, la idealidad y la unidad que ella mantiene en su segura comprensión totalizadora. La composición de la tesis descrita no se afecta por esta descomposición fragmentaria, a tal punto que su fecundidad debe ser interpretada de manera global. Comprometido con esta tarea, la cumplo en los cinco fragmentos que se dedican a continuación.

Asumo, por de pronto, que la CPC 1991, al igual que todas las Constituciones escritas, presenta los mismos problemas que se derivan de la lengua: la ambigüedad, la consideración genérica, la abstracción y la falta de determinación. La interpretación constitucional pierde su posición y deja de ser tal cuando ella se rinde, al no emplear las palabras acertadas, y se coloca fuera del perímetro de la lengua constituyente. Por eso, antes de justificar mis ideas, si se me preguntase acaso si en "la sentencia" la posición vencedora dentro de la CCC, por simple agregación de preferencias, contiene la respuesta correcta, afirmaría que las preguntas jurídicas pueden tener varias respuestas.

En este estudio, la interpretación dogmática intenta reducir el ámbito de la indeterminación y proveer una solución suficientemente comprensiva de la vaguedad, la abstracción y la generalidad. Es cierto: causará desilusión descubrir que el jurista no ha de proponer respuestas correctas, porque las propiedades del orden jurídico pueden originar la presencia de varias soluciones, en caso de que las hubiere en la realidad objetiva. Las soluciones, en la realización de los órdenes jurídicos constitucionales, a veces contienen respuestas monovalentes; en otros casos, bivalentes y también polivalentes; no obstante, la multiplicidad se ha de agotar cuando la interpretación arrase con la lengua constituyente. Por consiguiente, lo señalado configura el marco de referencia discursivo para "la sentencia". Mi respuesta concluyente -hasta nuevo aviso- se articula como 
conjetura fundada, que, quizá, fuese o pudiese ser refutada por la vía de su desestructuración o de un nuevo progreso en el conocimiento.

\section{IV.A. Defensa del poder ciudadano}

La regulación, en la propia lengua de la Constitución, del acuse de inconstitucionalidad formal del proceso detallado sobre o respecto del cambio de la ley fundamental y la determinación de la autoridad que deberá resolver el conflicto jamás debería significar una solución cuyos rasgos impliquen la inestabilidad de la fuente de poder ciudadano, su inferioridad o, peor aún, su letal descuido o abandono.

La lengua prescriptiva que asuma la Constitución de un Estado tiene varias propiedades: instituye un modelo único e irrepetible; alberga decisiones de filosofía política, muchas veces de diferente fuente, socialista o liberal, progresista o conservadora, e instaura un orden jerárquico de normas y las escalona en grados inferiores. La Ley fundamental de Colombia de 1991 ha cubierto todos esos aspectos y estableció un mundo constitucional. Un escenario mundano de reglas constitucionales para ser comprendido, observado y acatado por los ciudadanos y por los servidores públicos. Todo esto queda protegido con la normatividad de la CPC 1991. Más claramente, no hay más Derecho constitucional que el determinado por la Ley fundamental de 1991 y sus procesos de variación.

La lengua escrita por el poder constituyente colombiano de 1991 recrea, con fidelidad, su verdadero y único presupuesto instituyente: los ciudadanos que integran el pueblo. En su artículo 3 dispone para su propia eternidad que "[1]a soberanía reside exclusivamente en el pueblo, del cual emana el poder público. El pueblo la ejerce en forma directa o por medio de sus representantes, en los términos que la Constitución establece". En el concierto sudamericano el enunciado citado es uno de 
los más bellos, rigurosos y enfáticos. Nadie debería tener dudas respecto de la fuente del poder de configuración normativa. Porque ese pueblo, el colombiano, ha determinado conducir las existencias de los individuos con un riguroso marco de referencia normativo, la Ley fundamental de 1991.

La lengua de la CPC de 1991 también fue preparada por el poder constituyente fundador para el tiempo y el espacio futuro. Así, identifica con nitidez el protocolo de variación en el artículo 374: "La Constitución Política podrá ser reformada por el Congreso, por una Asamblea Constituyente o por el pueblo mediante referendo". Aquí también queda clausurado el orden constituyente de la Ley fundamental colombiana: no hay más vías o procesos para reformarla que los descritos y determinados por ella misma. Cualquier cambio que se intente fuera del proceso aludido queda fuera de la cosmología de la CPC 1991. Ella introduce en el orden jurídico un modelo propio, autorreferente y extraordinariamente preservador y conservacionista de su ideario prescriptivo, porque hace mucho más compleja su variación, si se la compara con la legislación cotidiana y ordinaria.

Así, quedará fatalmente decepcionado el sujeto que intentare un cambio, más allá de la protocolización señalada para la reforma constitucional. Ya sea que se tratare de un héroe o de un traidor, podrán cambiar la CPC 1991, pero su escritura no podrá ser reformada fuera del detalle ordenado en el Título XIII de la Ley fundamental de 1991. Con otras palabras, y para no descorazonar a nadie, no hay más reforma que la variación determinada en los artículos 374 a 379.

La reforma de la Constitución, como proceso normativo, protocolizado e indisponible, carece de un modelo único. Mejor todavía: no existen dos Estados en el mundo entero que posean idéntico proceso de variación constitucional ${ }^{14}$. La reforma constitucional, una verdadera apertura al tiempo, puede ser utilizada para "adaptarse" a procesos evolutivos que ya se han producido

14 V. Vergottini, Giuseppe de: Derecho constitucional comparado, Buenos Aires, Universidad, 2005, pp. 174-196. 
en los hechos, pero también puede "inducir" tales procesos de cambio ${ }^{15}$. La variación constitucional autoriza el desarrollo de la Ley fundamental.

Pero hay más sobre la lengua instituida propiamente por la CPC 1991. Una cuestión que puede ser discutible casi al infinito. Así, la lengua constituyente de 1991, para proteger o tutelar su pureza normativa, estableció el control jurisdiccional para las reformas "sólo por vicios de procedimiento en su formación", según se ordena en los numerales 1 y 2 del artículo 241. La determinación del poder constituyente originario de incluir en la textura el acuse de inconstitucionalidad de una reforma "sólo por vicios de procedimiento en su formación" introduce una extraordinaria singularidad para la lengua constitucional colombiana de 1991. Esta cuestión remite, inexorablemente, a los límites del proceso de variación.

Los límites de la reforma se presentan como un asunto de radical importancia, porque su existencia o inexistencia determinará, a su vez, la posibilidad de inconstitucionalidad (o no) de una variación constitucional. Además, los límites definen la "unidad" de la Constitución y sus posibilidades normativas. La discusión sobre los límites de una reforma constitucional concita la atención, en grado máximo, en la literatura constitucionalista.

Por de pronto, por "límites" he de entender, conceptualmente, los linderos dentro de los cuales debe transitar la creación del poder reformador constitucionalmente reglado ${ }^{16}$. Asumo la doctrina que asimila que el poder de reforma de la Constitución es un poder en la medida y justeza de sus límites, y más allá de estos lindes deja de ser una competencia establecida para convertirse en una pura fuerza.

La lengua adoptada por la CPC 1991, en particular en los incisos 1 y 2 del artículo 241, aunque no utilizan el término

\footnotetext{
15 HäBerle, Peter: El Estado constitucional, México D.F., UNAM, IIJ, 2003, p. 140.

16 Aláez Corral, Benito: Los límites materiales a la reforma de la Constitución española de 1978, Madrid, CEPC, 2000, p. 167.
} 
"formales", sin sospechas los sacraliza; se quiere abordar el problema de los límites formales, cuando se emplea el enunciado normativo "sólo por vicios de procedimiento en su formación". Evidentemente, en la CPC 1991 no hay ningún filón para imaginar "límites materiales" al poder de reforma, al menos, con el estilo explícito que ha fundado la Constitución brasileña de 1988, en su artículo 60. En semejante sentido, en la CPC 1991 tampoco se observan reglas irreformables, con el estilo auroral del artículo 139 de la Constitución de Italia de 1947 o del artículo 89 de la Constitución de Francia de 1958, o del artículo 79, apartado $3^{\circ}$, de la Ley fundamental de Alemania de 1949.

Los límites formales instituyen a qué órganos calificados compete y a qué procedimiento específico debe atenerse la realización de la creación constitucional reformadora ${ }^{17}$. Los límites del mundo jurídicamente posible, inaugurados a partir de la CPC 1991, son puestos por su lenguaje ${ }^{18}$. La elección por un determinado órgano y por un determinado proceso establece una cuestión que afecta la competencia, limitada, de la reforma de la CPC 1991.

Los límites formales, identificados en el artículo 241, incisos 1 y 2 de la CPC 1991, sólo por vicios en el procedimiento de formación de la reforma, no son un mero encaje, porque ellos conjugan y determinan la canalización y estabilización de las preferencias de los ciudadanos. Los límites formales, como procedimiento reglado en la CPC 1991, no son un mapeo ni una tímida insinuación, ya que instituyen, sin dudas, el propio desarrollo de la normatividad de la Ley fundamental. Los límites formales integran la lengua constituyente de 1991 y significan una privación, dado que solamente se puede seguir -si se ha de perseguir la constitucionalidad- el territorio formalizado para el cambio este proceso detallado y jamás otra especie de variación.

17 Cfr. Ross, Alf: "On Self Reference and Puzzle in Constitutional Law", Mind, Vol. 78, Issue 309, Oxford University Press, January 1969, p. 1.

18 Cfr. Wittgenstein, Ludwig: Tractatus Logico-Philosophicus, ob. cit., p. 153. 
La autoridad de la CPC 1991 incluye como parámetro básico para su regularidad el cumplimiento de límites formales al proceso de variación. Además, en el artículo 379 se dispone que "Los Actos Legislativos, la convocatoria a referendo, la consulta popular o el acto de convocación de la Asamblea Constituyente, sólo podrán ser declarados inconstitucionales cuando se violen los requisitos establecidos en este título"(Repito: el "XIII").

Se puede discutir, como lo hago luego, sobre el acierto o desacierto de instituir a la CCC con semejante responsabilidad institucional. No puede discutirse, en cambio, ninguna simultaneidad de sentidos. La CCC tiene atribuciones sólo para conocer sobre vicios en el procedimiento de formación de la reforma; hasta allí la competencia resulta indiscutida. No obstante, carece de atribuciones constitucionales para conocer respecto de la vulneración de un límite material o, peor todavía, en el marco de una enjundiosa e indescifrable doctrina de la sustitución ${ }^{19}$ que no tiene cabida en la positividad expresa y determinada de la lengua fundamental colombiana de 1991.

La doctrina de la sustitución de la Constitución, aunque reposare en determinados pilares o ejes definitorios, no se encuentra en la nomenclatura positiva de la lengua autorizada por la CPC 1991. Pese a que pareciere portar alguna riqueza, sin dudas su contenido es una verdadera "isla misteriosa", cuya develación depende de la subjetividad del juez que discierna,

19 La doctrina de la sustitución de la Constitución ha sido confiadamente realizada desde 2003 hasta el presente por los jueces de la CCC. Originalmente, se limitó a la infracción de límites formales. Luego, con el pergamino de los vicios de competencia, se ha extendido al control de límites materiales o de contenido de una reforma, tal como se analiza en el cuerpo principal, respecto de "la sentencia". En un listado meramente ejemplificativo, menciono las siguientes sentencias: C-971, de 2004; C-986, de 2006; C-153, de 2007; C-427, de 2008; C-588, de 2009; C-574, de 2011; C-846, de 2012, C-010, de 2013, y recientemente la C-630, de 2017. La citación de la jurisprudencia, además del valor heurístico, quiere llamar la atención sobre una consistente continuidad en el desarrollo de la doctrina jurisdiccional. La CCC, con diferentes integraciones, ha dado singulares pasos sobre esta cuestionable doctrina jurisdiccional. Obviamente, no es una doctrina "cerrada" ni completa, porque la elaboran los jueces de la CCC en el "cielo" de los conceptos abiertos, cuya producción reside en su propia voluntad discrecional. 
eventualmente, un asunto vinculado con la regularidad formal del proceso de reforma.

No hay normatividad constitucional que guarde a la doctrina de la sustitución. No existe definición de competencia para que la CCC se arrogue el conocimiento de una nueva categoría: "vicios de competencia en la reforma constitucional". El establecimiento de la CPC 1991 instituye a la CCC. La lengua constituyente ha definido al órgano CCC; si se entendiere que la CCC define sus competencias, no existiría tal órgano sino un órgano a cargo de una competencia omnisciente con habilidad institucional para determinar las competencias de los poderes constituidos. Con un juego de palabras: la competencia sobre las competencias.

La autoridad que atribuye el artículo 241, en sus incisos 1 y 2 , en tanto se la vincula sólo con los vicios en el procedimiento de formación de la reforma, introduce, por sí misma, una entelequia discutible. Esta señal opinable no salda la discusión sobre la regularidad del proceso formal por el hecho de que lo estudie y juzgue la CCC. Frente a este fenómeno -el control de la regularidad formal de la reforma constitucional, típicamente colombiano-, correspondería preguntarse, sin vacilar, si la atribución de tanta autoridad jurisdiccional no daría lugar a una tempestad de poder.

La CPC instituye una determinada normatividad. Así como la reforma de la Ley fundamental se encuentra ceñida a una conjugación específica e indisponible, lo mismo ha de entenderse respecto de la competencia de la CCC. No desconozco que pudiesen existir límites materiales implícitos indeterminados, todavía, pero susceptibles de ser captados en la CPC 1991. Probablemente, una segunda reelección de un presidente destruiría el sentido de la "república" instituida por la Ley fundamental.

El presidencialismo no me causa ninguna simpatía. Hay suficientes razones para vincular las desgracias de sistemas de gobierno con la ausencia de democratización del modelo presidencial. Admito, además, que tal conducta (la tentativa de una 
segunda reelección presidencial) podría ser entendida como pulverizadora de un "principio de naturaleza estructural" de la CPC 1991: la institución de la "República". Frente a tales desvelos institucionales, sin dudas que a nivel dogmático hubiese marchado, debatido y escrito en contra de la posibilidad de una primera reelección presidencial (como sucedió con Uribe en 2006). Mucho más, por cierto, contra la intentona de una segunda reelección presidencial consecutiva, un calvario para el itinerario ciudadano.

Sin embargo, con igual sinceridad debo confesar que la CCC no tiene competencia constitucional para conocer sobre la transgresión de dicho "principio estructural" (la renovación de las autoridades republicanas), por la sencilla razón de que la lengua engendrada por el poder constituyente en 1991 no habilitó su competencia para conocer en tal asunto. El gobierno constitucional es un gobierno limitado por la propia Ley fundamental. Si no existiesen límites, no sería el gobierno de un Estado constitucional. Todos tienen límites: los ciudadanos y los servidores públicos, en cada una de sus tareas.

Más allá de las buenas intenciones, la CCC, al considerar que ese órgano puede entender en el conocimiento de una reforma en ciernes y en un ámbito no reglado por la CPC 1991 para sus atribuciones, ella misma engendra una nueva versión de la lengua constitucional y dispone que ha de conocer porque hay vicios de competencia que desnaturalizan elementos estructurales del Estado.

La institucionalización, en la CPC 1991, de los conflictos que se suscitaren en y como consecuencia de la variación constituyente se remonta con seguridad a la propia historia jurídica del Estado. Sin embargo, sostengo que tal asignación de responsabilidad institucional a la CCC debe ser interpretada con suma prudencia. La ampliación del ámbito de conocimiento de la CCC sobre los procesos de regularidad en la formación de una reforma -repito: más allá de la taxativa nomenclatura del art. 241 , incs. 1 y 2 y por su propia voluntad-compromete de manera directa la estabilidad del poder ciudadano. Esto es así 
porque ese pueblo colombiano, integrado por sus ciudadanos, constituye la fuente del poder para elegir a sus representantes, y que éstos desarrollen sus tareas en el ámbito ceñido de sus competencias. Si los jueces, los presidentes o los legisladores creasen con actos de pura voluntad la zona de sus competencias constitucionales, el ciudadano quedaría en notoria inferioridad. En ese caso, la Constitución, en tanto código de restricciones al poder, se convertiría en un artefacto descuidado. Incluso, hasta quizá debiese ser abandonado, porque no cumpliría su principal tarea: determinar el ámbito de la libertad, de la igualdad y de la solidaridad para proceder a un encapsulamiento del poder.

La CPC 1991 impone límites a ciudadanos y servidores. Todos esos límites son explícitos, ya que la objetividad indubitada del Derecho alienta las posibilidades respecto de su siempre inalcanzable certeza absoluta. La lengua constitucional de 1991 es la que determina los "límites"; no son los servidores públicos -llámense jueces, presidentes o legisladores- quienes deben producir esos "límites", más allá de sus encargos prescritos en la Ley fundamental. Si acaso lo hiciesen, se vaciaría de sentido la idea de Constitución como instrumento reglado para permitir las existencias, en paz, de la ciudadanía.

IV.B. El peligro de cercenar la palabra pública de los ciudadanos

Constituir a la autoridad jurisdiccional en árbitro supremo de la política comunitaria impediría la liberación horizontal de la palabra pública de los ciudadanos.

La Constitución no es una hoja de papel, ni deja todo librado a la pura gobernanza de lo fáctico. Ella evoca un significado político, como ningún otro de los términos que emplea el Derecho objetivo en el discurso estatal. La Ley fundamental colombiana lo expresa maravillosamente, porque ella es la "constitución política" del Estado. No es caprichoso, en consecuencia, que el constituyente de 1991 haya acudido al inusual 
expediente de titular la norma fundamental como Constitución Política de Colombia, al atender a la santísima idea de que en todo momento la Ley de leyes debe consultar las transformaciones políticas de la sociedad. Su propio apodo, "política", acaba con la discusión.

En toda comunidad política organizada se necesita que se instituya una autoridad para "decidir todas las controversias"20 que puedan surgir con respecto al acatamiento a su Derecho; en especial, al Derecho constituyente que emana de la Ley fundamental. La determinación de un proceso y de un modo de solución determinado para las controversias resulta elemental para garantizar la paz social. A la jurisdicción se asigna, por lo general, la resolución de conflictos y el control de constitucionalidad; también, el gobierno de la judicatura, aunque en estos casos la tarea, a veces, es concurrente con los departamentos políticos $^{21}$. Sin embargo, las dos funciones -control de constitucionalidad y decisión sobre los conflictos-, que caracterizan a la propiedad básica de la jurisdicción, se encuentran vinculadas entre ellas, sobre todo por el hecho de que la primera (el control) siempre se desenvuelve en el marco de la segunda (un conflicto).

En consecuencia, dado un orden jurídico constituyente de un Estado, las disputas que se susciten con motivo de su mantenimiento o de su desarrollo serán siempre políticas. El Derecho constituyente es puro poder político concretado o "poder realizado"22. Por lo tanto, asumir que las cuestiones constitucionales son cuestiones políticas -sobre todo cuando se presentan como disputas- significa que tienen este aditamento, "políticas", no por una vinculación con un partido, una fuerza o una asociación, sino por el hecho de que se demandan para

20 HoвBEs, Thomas: Leviatán. 0 la materia, forma y poder de una república, eclesiástica y civil, México D.F., Fondo de Cultura Económica, 2011, p. 147.

21 V. Zaffaroni, E. Raúl: Estructuras judiciales, Buenos Aires, Ediar, 1994, p. 59.

22 Hauriou, Maurice: Principios de Derecho público y constitucional, Madrid, Reus, circa 1929, p. 283. 
sostener un orden jurídico creado por un acto constituyente político. Las disputas, en particular cuando se demanda el control de constitucionalidad, son disputas sobre Derecho positivo, en las que se asumirá la existencia de procesos y contenidos reglados; aunque se trata de controversias jurídicas, su esencia es inimaginable e irremontable sin la política.

Los actos jurisdiccionales son actos inherentes a la soberanía del Estado por intermedio de los cuales se protege o se desarrolla su orden jurídico. La garantía de constitucionalidad, sobre todo cuando se ejerce para declarar la nulidad o anulación de un acto o proceso, contiene puro ejercicio de una función "legislativa"23. Un ejercicio negativo del poder de configuración jurídica. El órgano jurisdiccional, cuando anula o nulifica un acto o una norma, debe trazar también una concepción abstracta, genérica y universal, pero en sentido negativo. La confección de la declaración de inconstitucionalidad de una norma o de un acto constituye una tarea política, porque se tratará de la partida de defunción del Derecho atacado, viciado y disconforme.

La tarea de interpretación, en el marco del control de constitucionalidad, es ardua, delicada y compleja. El juez constitucional integra el "sistema de autoridad dentro del Estado" ${ }^{4}$, pero, antes que eso, es un ciudadano de esa misma comunidad, que tiene comprensiones sobradas sobre cada una de las partes de la Constitución. El juez tiene una ideología, no es neutral; sin embargo, se espera que actúe con imparcialidad e independencia y dentro del contenido de la Constitución, cuyas piezas normativas han sido construidas por una o varias ideologías concurrentes.

En el marco del control de constitucionalidad, tampoco es neutral la Ley fundamental, objeto de la interpretación jurisdiccional. Sus directivas jamás lo podrían ser por definición propia. El Derecho constitucional, una vez puesto en el mundo, asume

23 Kelsen, Hans: “La garantía jurisdiccional de la Constitución”, en Revista Iberoamericana de Derecho Procesal Constitucional, México D.F., 2008, p. 24.

24 V. Zaffaronı, E. Raúl: Estructuras judiciales, ob. cit., p. 109. 
una verdadera configuración dinámica. Objetivamente, como elemento mundano, puede ser entendido como un verdadero tren en pleno movimiento ${ }^{25}$ : será muy difícil que sus pasajeros (ciudadanos y servidores) sean capaces de mostrar neutralidad por el reputado hecho "físico" de la marcha de su movimiento. No obstante, frente a un problema agudo sobre la constitucionalidad, no será un disparate intuir que correspondería aguardar una probable orientación interpretativa de un juez con ideario socialista y otra distinta de un juez más inclinado a las ideas liberales.

Vale aclarar que la CCC tiene un poder distinguido y sobresaliente en el escenario jurisdiccional de la CPC 1991. Sus poderes son notables. Se le confía la "guarda de la integridad y supremacía” de la propia Ley fundamental de 1991, en la estricta y precisa competencia atribuida en el artículo 241 ya citado.

Evidentemente, el poder constituyente auroral de 1991 se inclinó por un árbitro para el proceso de la Ley fundamental. Así, se le encomienda a la CCC una misión insustituible, irrenunciable y casi divina: la tutela de todas las piezas para que la Ley fundamental no carezca, jamás, de ninguna de sus partes. Además, otro compromiso celestial: protegerla frente a la invasión de su superioridad, como norma de normas, en el orden jurídico.

La política es un emblemático "arte" ${ }^{26}$ que denota las capacidades y las incapacidades, las habilidades y las debilidades, los éxitos y las frustraciones; en fin, el bienestar o el malestar general que los ciudadanos pueden disponer sobre los problemas comunitarios, cómo solucionarlos, cómo administrarlos y, también, quizá, la quimera de cómo evitar las repetidas caídas en dilemas. Así, en la comunidad la política jamás tiene descanso. En el ámbito del Estado todo es político. Todas las

\footnotetext{
25 Zinn, Howard: Nadie es neutral en un tren en marcha. Historia personal de nuestro tiempo, Guipúzcoa, Hiru, 2001.

26 Bunge, Mario: Filosofía política. Solidaridad, cooperación y democracia integral, Madrid, Gedisa, 2009, p. 85.
} 
horas del tiempo infinito, en todos los espacios en que pueda ejercer su imperio y su coerción jurídica. Toda felicidad de la comunidad es política. También las desgracias que, a menudo, en la vida citadina son más duraderas y menos frágiles que la dicha y la prosperidad.

En este ensayo, apenas una línea de esos problemas -el enjuiciamiento de la reforma constitucional- constituye una competencia atribuida a la CCC, en el artículo 241 de la CPC 1991, incisos 1 y 2 . Por eso, todo cuanto se expone aquí concierne de manera fundamental al control de constitucionalidad sobre una reforma de la Ley fundamental; aunque algunos argumentos podrían aplicarse, eventualmente, a semejante práctica que se ejerce sobre leyes, decretos o cualquier otro acto o norma que pugne con la Constitución.

La CCC dispone de una autoridad política arbitral. Una competencia de cepa constitucional y de vanguardia jurídica. En el juego de la política, su competencia para entender en el campo de la regularidad de la variación constitucional "sólo por vicios de procedimiento en su formación”, en la inteligencia descrita por los incisos 1 y 2 del artículo 241, muestra el cenit de la autoridad de la CCC en el ámbito de la CPC 1991.

La CCC, por purísima decisión del poder constituyente, tiene un rol de control del discurso político de configuración reformadora de la CPC 1991. Una inteligencia de la lengua de la CPC 1991 singulariza su posición de garante de la constitucionalidad de los aspectos formales del proceso de variación. Los jueces de la CCC pueden colegir, con razón, que el sujeto político por antonomasia, la ciudadanía que integra el pueblo representada por sus asambleístas constituyentes, le confirió una competencia eminente: proteger a la Ley fundamental en el proceso de variación por vicios de forma (de "procedimiento en su formación").

Esa práctica distinguida, el control de constitucionalidad de la enmienda en cuanto a su procedimiento, se incuba en una facultad del órgano, la CCC. Tal competencia debe ser 
ameritada con ajustada prudencia. La lengua de la CPC 1991 es bien parca al conferir esta competencia trascedente a la autoridad de la CCC. ¿Cómo pensar e individualizar un vicio en el procedimiento de formación? Con rigor, ¿cómo determinar el ámbito estricto de la autoridad de la CCC? Hay un solo camino para no convertirse en un "pasajero errante": considerar que el vicio en el procedimiento de formación debe tratarse de una "patología manifiesta" 27 , fruto de un escrutinio riguroso y sometido a pruebas contestes. Hay vicio siempre que provenga de una fuente evidente, manifiesta e insospechada. Nunca se debería juzgar un vicio no manifiesto, que no sea de comprobación concluyente.

La autoridad jurisdiccional de la CCC, en el caso del enjuiciamiento del procedimiento de una reforma, siempre afrontará hipótesis altamente conflictivas. Muy pocas Constituciones en el Derecho comparado han dispuesto recorrer ese camino. La CPC 1991 es un ejemplo normativo en ese sentido.

A la CCC, por lo tanto, le corresponde administrar su arbitrio, en la zona de conflicto poseída por un vicio en el procedimiento de formación de una reforma, con prudencia, y rescatar a la Ley fundamental siempre que la patología -repitosea manifiesta. Es cierto, mis ideas no son otra cosa que una interpretación. Pero cualquier otra que amplíe sus límites más allá de la naturaleza manifiesta mostrará, progresivamente, su fragilidad estructural, al no compadecerse con la atribución de los incisos 1 y 2 ("precisos y estrictos") del citado artículo 241.

La CCC es un árbitro. Pero la lengua de la CPC 1991 no lo ha convertido en un árbitro supremo que podría ubicarse por encima de su propia normatividad instituyente. Disiento con la decisión adoptada por la "mayoría" en "la sentencia". Una vez cuestionado el procedimiento de una reforma, ciertamente la variación jurídica del más alto rango quedará en una

27 THAYER, James: “Origen y alcance de la doctrina estadounidense del Derecho constitucional" [1893], Revista Derechos en Acción, La Plata, trad. Mariano Vitetta nº 7, 2018, p. 110. 
encrucijada bien compleja. ¿Cómo encontrar un proceso para el enjuiciamiento de la reforma que deje a todos los actores satisfechos cuando ningún proceso de toma de decisiones finales va a ser perfecto ${ }^{28}$ Es mucho más complejo todavía cuando el problema asumido comporta un límite material implícito, un vicio de competencia que trasluce la desnaturalización de un principio estructural, según confiesan los jueces que suscriben el voto de la "mayoría".

No hay ninguna razón, escrita o no escrita, para que un conjunto de jueces impidan el ejercicio del principio de autodeterminación ciudadana, cuando es indefectible que ello deba proceder y suceder. "La sentencia" ha impedido y desnaturalizado la autodeterminación política comunitaria. Ella inhibió a los ciudadanos que integran el pueblo de la majestuosa, única e irrepetible obra de la democracia constitucional: concurrir a las urnas y liberar su expresión política. También lo inhibió de participar de actos políticos antes de una elección que nunca tuvo espacio ni tiempo.

Los jueces que asumieron la "mayoría" en "la sentencia" actuaron como árbitros supremos del proceso político. No pareciera una comprensión que se derive de la ordenación de la CPC 1991, aunque desde luego ha tenido profundas consecuencias: que los ciudadanos no hayan podido elegir. Desdecir, pues, el principio de autodeterminación política comunitaria implica no abrir paso a un derecho fundamental del ciudadano. La decisión de la CCC, con el peso de su imperativa y vertical de la coerción, cercenó el despliegue horizontal de la palabra genuina de los ciudadanos. Así, los integrantes de la CCC, que decidieron la "mayoría", mostraron ser árbitros supremos dotados de una inherente supremacía jurisdiccional que colocó en una suerte de ocaso el derecho a la participación de los individuos en el referendo constitucional. En suma, los ciudadanos no pudieron

28 WaLdRON, Jeremy: "El centro de la argumentación contra el control judicial de la legislación", en AA.VV.: Filosofía del Derecho constitucional. Cuestiones fundamentales, México D.F., UNAM, IIJ, 2013, p. 179. 
votar en el referendo y tampoco en una elección posterior, en el caso de que hubiesen deseado "premiar" con un tercer mandato consecutivo a Álvaro Uribe Vélez.

IV.C. Falta de distinción entre poder constituyente y poderes constituidos

A su vez, queda sin diferencias la distinción entre poder constituyente y poderes constituidos, solución extraordinaria que se sitúa fuera de la autoridad de la Constitución y de cualquier argumentación razonable, porque se admitiría una "contrarreforma" por vía jurisdiccional al manifestarse un ejercicio de poder constituyente derivado, ciertamente, no electo por el pueblo para cumplir tal alteración.

El emplazamiento del poder del Estado, en la cuna constitucional, autoriza la conjetura de que el Derecho que emana de la Ley fundamental es supremo, no así el poder envasado por ella. En esta génesis se postula la supremacía del Derecho constitucional, no del poder. Los dos, Constitución y poder, no deben ser supremos en un Estado. Sin la supremacía de la normatividad de la Ley fundamental, no resulta factible escalar y sostenerse dentro de la ilusión del Estado constitucional. Porque el poder, sin los límites y vínculos constitucionales, se desplazaría por cualquier territorio y en cualquier momento con contenidos voluntarios. El gobierno del Derecho por encima del gobierno de los hombres sólo se hace posible con la subordinación a la Ley fundamental.

De manera precisa, la Constitución, con sus límites y vínculos, instala un determinado proceso de ejercicio del poder, sea éste de naturaleza "constituyente" o de naturaleza "constituida", es decir, de naturaleza "constituyente-constituido". La razón del Derecho constitucional se debe imponer sobre la voluntad política pura del poder. En caso de no suceder, gobernarían los hombres, no el Derecho. 
El poder constituyente, al que se atribuye la pura creación política de la Constitución, se distingue del poder constituido, porque la energía de aquél es excepcional. Sólo se ejerce en los momentos constituyentes -que no son cotidianos ni ordinarios-, dedicados por completo a la configuración constitucional.

Por lo tanto, el poder constituyente, siempre se desplazará por la propia textura de la lengua de la Ley fundamental. Además, el poder constituyente reformador de la CPC 1991 puede ser descrito como a cargo de un "órgano constituido" (si la reforma la lleva a cabo el Congreso), o de un "órgano constituyente derivado" (si la reforma la lleva a cabo una Asamblea), o mediante una verdadera zona mixta (si la reforma se posibilita por la vía del referendo ciudadano). Sin embargo, la reforma de la Ley fundamental colombiana de 1991 siempre será producto de un poder constituyente, el que podrá ser "constituido", "derivado" o una conjunción de ambos. No hay más procesos para reformar la CPC 1991 que los referidos.

Por de pronto, el hecho de que el poder constituyente, ejercido en sede constituida o derivada, sea una energía completamente excepcional y reglada responde a la distinción entre razón y voluntad. Así, la Constitución, en el caso de la Ley fundamental colombiana de 1991, demuestra que, una vez instaurada de manera autorreferente su normatividad, ello provocará que las emanaciones del poder -constituyente o constituido- siempre deban ser regladas, al menos si se pretende que el Derecho constitucional sea supremo al poder, como se propone desde esta comprensión.

El lazo constitucional resulta indisponible para los ciudadanos y para los poderes. La CPC 1991 limita con vínculos supremos, decisivamente, a ciudadanos y gobernantes. La existencia fuera de la CPC 1991 puede ser existencia, pero no será existencia constitucional razonada.

En el caso de los ciudadanos, se impone el artículo 3 de la CPC 1991, según el cual "[1]a soberanía reside en el pueblo, del cual emana el poder público. El pueblo la ejerce en forma 
directa o por medio de sus representantes, en los términos que la Constitución establece". El significado profundo del enunciado referido implica que el pueblo, a pesar de ser el depositario de la soberanía, cuando ejerce el poder de reforma constitucional también debe actuar dentro del marco procedimental y de competencia fijado por la propia Constitución. El pueblo queda atado a la Constitución de 1991 y, por lo tanto, no puede modificar sus elementos definitorios cuando actúa en el ejercicio del poder de reforma. En otras palabras, el pueblo podría desatarse de los elementos definitorios de la CPC 1991, pero nunca podría peticionar que ese desajuste, una salida sin retorno, se empalme con una reforma de la Ley fundamental, porque ello implicaría un verdadero desbarajuste abolicionista.

Además, la regla contenida en el artículo 94 de la CPC 1991, en tanto "La enunciación de los derechos y garantías contenidos en la Constitución y en los convenios internacionales vigentes, no debe entenderse como negación de otros que, siendo inherentes a la persona humana, no figuren expresamente en ellos", no desvanece sino que debe ser conjugada en el ambiente propiciado por el principio capital reunido en el artículo 3. Así, pues, por imperativo del artículo 3 y su conjugación con el artículo 94, el poder ciudadano debe ser canalizado por la norma constituyente del Estado.

En el marco de la CPC 1991, el pueblo de Colombia no ha retenido o reservado derechos políticos para ser ejercidos por fuera de su significación constituyente. Ciertamente, la prevalencia del DIDH no es un mero pendón. En el orden constituyente colombiano, el pueblo y sus representantes quedan sometidos a su Ley fundamental y, en el caso de una reforma de ella, también, al límite heterónomo dispuesto por el artículo 93, en las condiciones allí expuestas.

Con la voz del Preámbulo, "[e]l pueblo de Colombia, en ejercicio de su poder soberano, representado por sus delegatarios a la Asamblea Nacional Constituyente", ha depositado todo su poder originario en la CPC 1991, pero ese "pueblo" deberá someterse a la lengua constituyente. Por cierto, en el 
futuro -repito- podría hacer lo que le placiere con su poder ciudadano constituyente, porque nunca se desprenderá de su totalidad, y hasta ir más allá de los límites de la CPC 1991. Sin embargo, si esto último sucediere, no sería una reforma de la lengua fundamental del Estado. Con seguridad se trataría de su abolición o derogación, ya que caería la secuencia de validación formal y material predeterminada con energía absoluta por la Ley fundamental colombiana de 1991.

No hay ninguna religiosidad al defender un constitucionalismo cuyo presupuesto reside en el poder de los ciudadanos que integran el pueblo. Un poder de configuración que, al ser ejercido, habitualmente por la vía de sus representantes, puede dar una Constitución, que servirá como fundamento del Estado. Entonces, ese Derecho constituyente, de fuente ciudadana, se convierte en presupuesto del Estado y esta asociación de ciudadanos, en la garante de la democracia.

Desde luego, los servidores que ejercen las diferentes ramas del Poder público en Colombia también son ciudadanos. Un servidor público no es una clase de ciudadanía especial; sólo ha sido distinguida para cumplir con los mandatos constitucionales. Así como los ciudadanos del pueblo se someten a la CPC 1991, la misma lengua instituyente debe someter el itinerario de la competencia específica de cada uno de los miles de servidores públicos. No hay servidores públicos por encima de la CPC 1991; si los hubiere, la Ley dejaría de ser fundamental y suprema.

En el artículo 113, la CPC 1991 refiere, genéricamente, que son ramas del poder público la legislativa, la ejecutiva y la judicial. Tales ramas del poder deben cumplir su cometido dentro de zonas específicas de actuación constitucional. El asunto ha sido analizado en "Dos", sección I. Deseo recordar, ahora, que allí donde el servidor público carezca de competencia instituida por la Constitución del Estado y ejerza un poder no reglado constitucionalmente, se estará en presencia de "pura voluntad, liberada e indisciplinada", que puede ejercer coerción, pero no podrá peticionar su naturaleza de Derecho constitucional. 
Al proscribirse la razón de la lengua instituyente del Estado, los dictados de su Constitución, se origina un camino incierto. Todos los servidores públicos deben cumplir sus tareas constitucionales, dentro del ámbito de la CPC 1991, en el campo normativo de competencias delineado para cada uno de ellos.

Así, como los ciudadanos no deben ejercer su poder fuera de la lengua de la CPC 1991, la misma condición se impone sobre los servidores públicos. Ninguna rama del poder del Estado debería considerarse por encima del Derecho que establece la CPC 1991. Insisto en que no deben existir poderes supremos sobre la supremacía de aquella Ley fundamental.

La "mayoría" vislumbrada por los jueces de "la sentencia" consideró disponer de una competencia jurisdiccional. Ahora bien, esa competencia no resulta atribuida por la CPC 1991, en las condiciones expuestas por esos mismos magistrados. De este modo, la reforma constitucional que se pretendía concretar fue impedida por imperativo jurisdiccional expresado por una mayoría de jueces de la CCC. Así, "la sentencia" se convierte en una verdadera contrarreforma: realiza una "actuación contraria a una reforma anterior" que se postulaba.

La contrarreforma contenida en "la sentencia", por mayoría de jueces de la CCC, produjo dos desprogramaciones: una, la sincera posibilidad de una reforma constitucional; otra, un ejercicio de poderes constitucionales no reglados de manera explícita. En "la sentencia", los jueces que conformaron la mayoría consideraron que el mundo de la CPC 1991 se salía sus goznes. Sin discriminaciones ni azares, fijaron su posición, que se proyecta en el ámbito de una asignación de competencias no dispuestas expresamente por la Ley fundamental de 1991.

Según ordena el artículo 239 de la CPC 1991, los jueces de la CCC no son electos de manera directa por el pueblo ${ }^{29}$. Tal procedimiento de designación no es, en sí mismo, una fuente

29 “Art. 239: La Corte Constitucional tendrá el número impar de miembros que determine la ley. En su integración se atenderá el criterio de designación de magistrados pertenecientes a diversas especialidades del Derecho. 
de deslegitimación. Sin embargo, pese a no ser elegidos directamente por el pueblo, han ejercido un poder constituyente, al contemplar una competencia de la CCC que no fue dispuesta por la CPC 1991.

Concluyo este punto no sin antes plantear una inquietud respecto de la contrarreforma por vía jurisdiccional que supuso la sentencia: “... ¿el Derecho de los jueces quién lo puede modificar? Si nadie lo puede modificar, excepto otros jueces, significa que el poder de los jueces se encuentra por encima del Derecho..." ${ }^{30}$. ¿Jueces más supremos que la CPC 1991?

IV.D. Limitar el poder de los jueces

Antes que pensar en las limitaciones al poder jurídico ciudadano para generar reglas jurídicas de la más alta estirpe, ¿no correspondería limitar el poder de los jueces?

El Derecho constitucional es un objeto de altísima tecnología social. No es eterno. Sus piezas, inacabadas por naturaleza, pueden ser reformadas en cualquier momento constituyente, gracias a un protocolo instituido para su variación. Los ciudadanos del pueblo de un Estado, al establecer la Constitución por la vía de la representación, deciden, como en el caso de Colombia, que el poder ciudadano constituyente ha de quedar institucionalizado en el propio orden jurídico que al nacer lo cobija en sus entrañas para su desarrollo.

Así, la Constitución, el cuarto elemento del Estado, puede convertirse en la pieza capital para favorecer la existencia de

\footnotetext{
"Los Magistrados de la Corte Constitucional serán elegidos por el Senado de la República para períodos individuales de ocho años, de sendas ternas que le presenten el Presidente de la República, la Corte Suprema de Justicia y el Consejo de Estado".

30 Boввı, Norberto: "Carta de Norberto Bobbio a Nicola Matteucci" [Breuil, 25/7/1963], trad. Vannesa Alejandra Pérez Rosales et al., Revista Derechos en Acción, n³ 3, La Plata, 2017, p. 327.
} 
los ciudadanos, el primero de los elementos y el fundamento comprensible de todo cuanto existe en cualquier comunidad.

La existencia humana, aplicable a la existencia individuada por los ciudadanos en la comunidad, no tiene misterios: es una existencia con conocimientos y aplicaciones de límites. Sin una conciliación de los límites, no hay reconocimiento del otro. Sin religiosidad por el respeto del otro ser humano, no hay constitucionalidad ni Estado democrático.

Por eso, la Constitución impone límites a los ciudadanos y a los servidores públicos. El constitucionalismo, como autoridad que disciplina todos los comportamientos en una comunidad, es una tarea que, en una sociedad abierta, incluye a todos; los jueces son uno de los sujetos de ese cuantificador universal ("todos") determinado para la realización de la Constitución ${ }^{31}$.

El paradigma de una sociedad abierta, en la que cada ciudadano pueda adoptar con igual libertad sus decisiones personales, conduce a esta conclusión: o todos realizan el Derecho constitucional, o el Derecho constitucional es simplemente una nueva forma de dominación; en este caso, perpetrada por una aristocracia dueña de cierto saber, no elegida directamente por los ciudadanos que integran el pueblo, cuya sabiduría nunca podrá ser puesta a prueba definitiva. La referencia alude al gobierno de los jueces.

La tarea de interpretar, incluso dentro del paradigma de realización que exige el control de constitucionalidad, instituye la sujeción del juez al Derecho que surge de la Ley fundamental. La búsqueda de la decisión en un caso siempre comporta espacios de libertad del magistrado, pero esto no establece ni mucho menos debería autorizar que esa decisión pueda ser el

31 Peter Häberle enseña que "La Constitución...es también expresión de un estado de desarrollo cultural, un medio de autorrepresentación de un pueblo, un espejo de su herencia cultural y un fundamento de sus nuevas esperanzas" HäBERLE, Peter: "La Constitución como cultura", Anuario Iberoamericano de Justicia Constitucional, nº 6, Madrid, CEPC, 2002, pp. 177-198. 
fruto de un espacio de discrecionalidad insumiso sin guardar correspondencia o comprobación con el orden jurídico.

El intérprete debe decidir el significado del Derecho constituyente puesto en el mundo, pero no debería configurar ese Derecho, porque carece de competencia para ello. Una tarea es configurar, otra realizar. Del mismo modo que una tarea es producir y otra aplicar. En sintonía semejante, no es lo mismo crear que interpretar. La interpretación constituye una tarea cognoscitiva del Derecho constituyente; no debería comportar ni su creación ni su producción ni su libre configuración. El objeto de la interpretación ha sido colocado, mundanamente, por el poder constituyente. Ése es el límite, razón por la cual no debería esperarse que el intérprete, en lugar de realizar el objeto, se ocupase de producirlo, en actos de libre disposición y voluntad.

El intérprete del Derecho constitucional, en el caso la CCC, debe conocer el asunto y, para hacerlo, debe adoptar decisiones significativas, las que siempre han de ser fundadas. No obstante, esa tarea cognoscitiva del juez constitucional -repito: auspiciada por un campo de libertad de actuación, porque no se espera que sea un autómata exento de complicaciones devenidas de la indeterminación de la lengua constituyente del Estado- no debería generar un acto de discrecionalidad libérrima sobre el Derecho. Estos últimos actos, cuya naturaleza es de franca ponderación política, en lugar de "realizar el Derecho" pueden llegar a "ignorar" las normas propiamente aplicables a la subsunción exigida, u originar el indeseado hecho de que se "puedan crear" 32 otras que no figurasen, ni capitalizadas en el orden jurídico del Estado, ni éste mostrase autorización expresa para que ello sucediere.

La jurisdicción constitucional se debe encontrar completamente ligada a la Ley fundamental. Como ya he señalado, frente a un caso constitucional existe la probabilidad de que exista más

32 Ferrajol, Luigi: “Constitucionalismo principialista y constitucionalismo garantista”, en Un debate sobre el constitucionalismo, Madrid, Marcial Pons, 2012, p. 48. 
de una respuesta. La concluyente debería ser la que ofrezca el mayor grado de verdad por su conformidad con la composición de la lengua fundamental. Para ello, por cierto, el juez constitucional enfrentará complicaciones derivadas de la semántica de la Ley fundamental, pero su espacio de discrecionalidad, aunque razonable, jamás podría culminar con un "poder del juez" que se convierte en un poder "creativo". Ello equivaldría a un "poder de disposición"33, reñido por completo con el sacramento establecido por la regla sobre la distinción de las funciones del Estado. Cuando el juez constitucional deja de lado la tarea de subsunción jurídica, discrecional y razonable, y se pone en marcha el denominado "poder de disposición jurídica", comienza un proceso de deterioro de la regla de distinción de las funciones del Estado que, además de lesionar la separación de poderes, debilita la legitimación de la magistratura, porque se escandaliza la regla sobre la subordinación del juez a la Ley fundamental.

El juez constitucional, dentro del marco de su estricta e irrenunciable sujeción a la Ley fundamental, no debería ampliar su discrecionalidad de modo libérrimo. Esto ocurre, acaso, si el magistrado concurre a la elaboración de un paradigma contrario a su estatuto y, así, crea reglas sin competencia para ejercerlo o ignora las aplicables al caso y que sí deberían ser objeto de realización.

La Ley fundamental establece un programa esencialmente normativo. Del desarrollo de su normatividad pende la ordenación, imprecisa, parcial e imperfecta, de las existencias individuales en la comunidad. La CPC 1991, como toda Ley fundamental, contiene límites precisos que vinculan de modo estricto la actuación de cada uno de los poderes del Estado. Sin competencias restringidas y sin zonas de reserva para las ramas del poder público, no hay Estado constitucional. Sin Estado constitucional será muy difícil pensar en la democracia como

33 Ibíd., p. 49. 
forma de conducción austera o de don político sobrio que guíe la existencia de las personas en la sociedad.

La vulneración de esos límites determinados por la Ley fundamental, verdaderos y singulares postes que intentan sostener su pura normatividad y hacerla creíble, conllevará, de manera inexorable, la caída de la regla sobre la subordinación; en particular, en cuanto ella intenta instituir la jerarquía de las fuentes, con la CPC 1991 en la cima del orden jurídico.

El juez constitucional no se encuentra autorizado para inventar reglas o principios constitucionales, porque, concretamente, hay un límite. Repárese, por de pronto, que en el artículo 241 de la CPC 1991, en sus incisos 1 y 2 se encuentra la respuesta. El verbo típico que ha de conducir la tarea del juez constitucional es "decidir". Con sinceridad, en el ámbito semántico de dicho verbo, resulta muy complejo incluir, con "carta de nacimiento", que la doctrina de la sustitución quedase abarcada dentro del "decidir" de un juez. Quizá se tratare de una decisión impropia que, al quedar caracterizada como una tarea de disposición, no encontrara anclaje en la CPC 1991, porque subvierte la jerarquía de las fuentes, al convertir a la CCC en poder constituyente.

La doctrina de la sustitución, tal como se expresa por la mayoría de los jueces en "la sentencia", configura una verdadera y propia "invención normativa" ${ }^{34}$. Por vía de la creación pretoriana, quizá fundado en el hecho de pensar que las reglas constitucionales no sean "rígidamente vinculantes, a las que se encuentra sometida la jurisdicción" 35 , cuando en rigor son indisponibles, se habilita una competencia de la CCC para decidir en el asunto y que no surge explícita del léxico constituyente.

La doctrina de la sustitución, sin dudas, ofrece pergaminos indisimulables y un destino encomiable. También sus fines, desde una comprensión teórica, puedan ser plausibles. No obstante, no hay en la CPC 1991 un punto para apoyarla, y menos todavía

\footnotetext{
34 Ibíd., p. 40.

35 Ibíd., p. 40.
} 
para justificar su itinerario jurisdiccional, en especial, cuando cancela la posibilidad de que se ejerza el poder ciudadano constituyente, tal como lo hizo "la sentencia".

La regla sobre la subordinación sujeta al juez a la Ley fundamental, mientras que la regla sobre la distinción determina los límites de su poder jurisdiccional. Por eso, las invenciones normativas que se ejerzan más allá de los límites de la prudente discrecionalidad del juez no podrían dejar de exhibirse en contraste con la Ley fundamental. La ampliación de los límites determinados por la CPC 1991 para el juez constitucional, cuando se produce en el espacio de la propia discrecionalidad jurisdiccional, no favorece la normatividad de la Ley fundamental, ni asegura su mantenimiento. Además, da lugar a un nuevo conflicto: la desnaturalización de la legitimación del magistrado.

"La sentencia" no favorece el ideal regulativo de la normatividad, porque promueve una lengua más allá de los límites determinados y guardados por la CPC 1991 para la institución de la competencia de la CCC. La discrecionalidad de los jueces, necesaria para conocer en todo asunto en que intervengan, nunca debería alcanzar el mismo ámbito que tiene la discrecionalidad política cuando resulta ejercida por el poder constituyente reformador. En el mismo momento en que los jueces dejan de subsumir y traspasan la discreción habilitada por la CPC 1991 para su encomienda constitucional, emprenden un poder de disposición sobre las reglas constitucionales. Eso provoca "la sentencia" sin indulgencia justificada.

\section{IV.E. Acerca del procedimiento de reforma constitucional}

La CPC 1991 ha confiado a los jueces de la CCC o al Congreso el deber de determinar la naturaleza, oportunidad y contenido de las enmiendas.

Toda Ley fundamental de un Estado reglamenta un propio universo jurídico, incluso, su programa para el cambio 
protocolizado. Actualmente, se podría afirmar que casi no existen Constituciones en el mundo que no engloben, en su seno, la descripción del proceso de su propia reforma en su propio texto. El alcance de las enmiendas de la Ley fundamental se decide en los momentos constituyentes. La naturaleza y la entidad del momento constituyente se inserta en la Constitución. A su vez, la posibilidad de una reforma parcial o de una reforma total de la Ley fundamental determina el contenido del cambio jurídico protocolizado.

Hay un único proceso para reformar cualquier Constitución: el modelo para el cambio instalado, de manera autorreferente, en su propia lengua. Fuera del protocolo determinado para el cambio de la Ley fundamental, no hay reforma constitucional posible. La subordinación que ha de generar la Ley fundamental al Estado significa que, si acaso se decidiere no seguir la juridicidad determinada para la reforma, dicho abandono eventual del protocolo, aunque parcial, jamás justificará una variación, porque se habrá provocado la ruptura de la secuencia de validación formal y material.

Además, la oportunidad para llevar adelante una reforma constitucional siempre será una decisión política. Esto es así porque la configuración constitucional ha de residir en la ciudadanía, quien la ejercerá, en general, por la vía de sus representantes, quienes a su vez deberán ser elegidos en comicios populares, auténticos y transparentes.

En pleno siglo xxI, aunque la Constitución deberá ser siempre comprendida como un bien colectivo de las generaciones de ciudadanos vivos, se conoce con plenitud el riesgo que supone abandonar o desnaturalizar la juridicidad constituyente, muchas veces instituida por ciudadanos que ya han partido para siempre. En rigor, al traspasarse sus límites, desaparece o se pone en crisis la magna idea del Derecho constitucional: conseguir y mantener la paz.

Recuérdese que Ley fundamental de Colombia de 1991 ha distinguido a la CCC con un rol trascendente en el proceso de 
reforma: "sólo por vicios de procedimiento en su formación". No tiene sentido preguntarse por las razones de haber determinado aquel rol trascendente para la CCC, porque merece cumplimiento estricto, tal como lo exige la CPC 1991. Simplemente, deseo acotar que la regulación del proceso de enjuiciamiento de una reforma constitucional, en las propias letras de una Ley fundamental colombiana, aunque no es una curiosidad en el Derecho constitucional comparado, tampoco es una decisión habitual que se ejerza en los momentos constituyentes de los Estados.

Aunque la CCC no ha de fungir como un constituyente o legislador positivo, revela su abanico de competencias como constituyente o legislador negativo. Así lo atestiguan y garantizan los artículos 241 (incs. 1 y 2) y 379 de la CPC 1991. Probablemente, en el momento constituyente originario de 1991, se haya pensado, con suficiente razón, que la existencia de límites fortalecería el proceso del constitucionalismo democrático. Dentro de ese marco, la limitación del poder de reforma, por el cuidado que a la Ley fundamental se le dispensa con el papel e intervención de la CCC para entender sobre los vicios de procedimiento en la formación del cambio, debe leerse como una regla capacitadora que podría dar mayor hondura al debate ciudadano y al político institucional.

En este contexto, sin embargo, no podrá leerse que la CCC, además, podría disponer de una aptitud de configuración positiva, dado que la CPC 1991 no le atribuye competencia jurídica para enhebrar una iniciativa política que se encamine por esa vía. La conclusión inevitable es que los límites jurisdiccionales (de la CCC) con los que se ha de enfrentar cualquier proyecto de reforma de la CPC 1991 presentan un ideario interesante en la lengua constituyente del Estado colombiano, que la singulariza en el Derecho constitucional comparado.

En todo caso, la atribución del control jurisdiccional de constitucionalidad sobre la regularidad de una reforma, en los casos de vicios en el procedimiento de formación, trae aparejada una meditación juiciosa sobre su entera y más completa razonabilidad. El veto jurisdiccional ejercido en tales instancias supone la 
clausura del debate sobre la configuración de la Ley fundamental. Toda discusión sobre la palabra pública tiene un comienzo y merece la adopción de una decisión final. Se hace necesario instalar un proceso solvente como regulación del cierre del debate.

Los jueces de la CCC no son vitalicios en sus cargos, porque han de ser elegidos para períodos individuales de ocho años y no podrán ser reelegidos, según se establece en el artículo 239 de la CPC 1991. Sin embargo, sus decisiones jurisdiccionales, en el marco de un proceso de enjuiciamiento de una reforma, por regla poseen una extensa afirmación en el tiempo superior, presumiblemente, a la duración de su encomienda en el cargo constitucional.

En el apartado anterior expresé que la intervención de los jueces de la CCC resulta relevante, trascedente e interesante. Ahora bien, no sorprenderé al lector si propongo, de constitutione ferenda y con el objeto de acentuar la luz hacia adelante, que esa toma de decisión final no debería ser captada sólo por el veto jurisdiccional, sino complementada con un llamado a la participación ciudadana: sí al diálogo, no al monólogo; japelación a las urnas electorales, no sólo a los tribunales!

Una convocatoria abierta a la ciudadanía, a tono con el estatuto desarrollado y justificado en esta obra, aumentaría la vocación deliberativa de la democracia con nuevas acciones afirmativas, cuya información detallada en el proceso preelectoral debería ser de cumplimiento insoslayable por el gobierno del Estado. Una propuesta que recorriese la estrategia planteada haría crecer la escala del debate ciudadano y, finalmente, gozaría del respaldo de una mayoría deliberativa de ciudadanos que la apoyaren.

La participación ciudadana, como última palabra del proceso de construcción o reforma, se puede vincular con cualquier proceso de dicha naturaleza detallado, lujosamente, en la propia CPC 1991 con su actual textura. Sin embargo -repito-, el argumento deslizado - la convocatoria a la ciudadanía para que emita su palabra final como último veredicto, en un verdadero y valedero acrecentamiento de la naturaleza dialógica de las decisiones comunitarias- sólo puede ser una fórmula ideal compatible 
con una futurible redacción de la CPC 1991. Mientras ello no suceda, mi argumentación sobre el llamado a la ciudadanía para acrecentar las votaciones y aumentar el compromiso y los acuerdos comunitarios debe ser entendido como una propuesta doctrinaria, una reflexión teórica. Para no ser acusado como un iconoclasta, recuerdo aquí elocuente dogmática en apoyo de la propuesta: "En ningún sistema el poder de los tribunales puede llegar tan lejos como para salvar a un pueblo de la ruina" 36 .

No existe argumento suficiente que sustente que el control para el enjuiciamiento de la constitucionalidad de una enmienda deba residir, con exclusividad, en el poder jurisdiccional. No es racional que el proceso de construcción política, concretamente su cierre, quede a cargo de la autoridad jurisdiccional, que no es elegida en comicios directos y populares. Con este mecanismo, que atribuye la última palabra a la sede jurisdiccional, los ciudadanos son meros espectadores. La construcción de un constitucionalismo ciudadano se basa en la responsabilidad, la tolerancia y el compromiso en el marco de una sociedad abierta. Esta apertura, precisamente, es el mejor indicador de que la realización del Derecho constitucional no debe ni puede quedar, exclusivamente, a cargo de los jueces. Juzgo atractiva, sugerente y plausible la obligación de que habría de disponer siempre "todo ciudadano para exponer las nuevas ideas" ${ }^{37}$ sobre el itinerario comunitario.

En los párrafos anteriores de este punto, he justificado que la CCC no dispone de iniciativa política para reformar la CPC 1991. La incompetencia señalada significa ausencia de energía positiva para motorizar una variación constituyente. No obstante, he afirmado que dispone de energía "negativa" para frenar un cambio en marcha, en tanto y en cuanto se comprendieren vicios en el procedimiento de formación de la enmienda.

\footnotetext{
36 Thayer, James: “Origen y alcance de la doctrina estadounidense del Derecho constitucional", ob. cit., p. 131.

37 IBSEN, Henrik: Un enemigo del pueblo, Buenos Aires, Colihue, 2010, p. 155.
} 
También sostengo la necesidad de que el debate sobre la configuración debería incluir -de constitutione ferenda y en el marco propiciado por los arts. 241, incs. 1 y 2 , y 379- un llamado o una convocatoria a la ciudadanía para que disponga, con propiedad y en el ámbito de los mecanismos contemplados por la democracia participativa, el modo concluyente que se haya de adoptar sobre la decisión final.

La resolución de la "mayoría" de los jueces en "la sentencia" canceló cualquier posibilidad dialógica. Nótese que en este caso la naturaleza dialógica se encuentra acreditada por la CPC 1991 (el referendo constitucional), que los jueces por mayoría dispusieron que no se realizara. De este modo, aquellos jueces tomaron, con voz propia, la última palabra institucional y descartaron oír a la ciudadanía, cuando la normatividad de la CPC 1991 no los autorizaba a crear un ámbito de competencia para aplicar la doctrina de la sustitución. Insisto en que "la sentencia" no fue la solución apropiada para clausurar la decisión sobre la segunda reelección de un presidente en ejercicio, porque se ensayó, por un lado, una competencia no reglada por la CPC 1991 y, por otro, no se habilitó la escucha majestuosa que sí se encuentra ordenada en la CPC 1991 para las decisiones ciudadanas, las que se podrían haber volcado en las rutinas electorales.

La voz de los ciudadanos que integran el pueblo, que emana de su altísima e irreprochable investidura, constituye el fundamento del poder del Estado. Del poder de la ciudadanía emerge y se desarrollan los poderes del Estado. Debería resultar inconcebible que existiese un poder del Estado más allá de la decisión nutricia de la ciudadanía que integra su pueblo.

"La sentencia", entre otros estados de cosas, alejó a los ciudadanos de la posibilidad de sufragar en un referendo constitucional. No había fundamentos para negar el ejercicio cabal de la democracia participativa. "La sentencia" se muestra, así, como una pieza que germina una semilla que encoge, y por eso incapacita el desarrollo de una ciudadanía plena y robusta. 


\section{Comentarios finales}

Primero. Los ciudadanos son pivotes y presupuesto del Derecho constituyente del Estado. No hay Ley fundamental sin ciudadanía. Así, un constitucionalismo con ese protagonismo se puede adjetivar como "ciudadano". Un "constitucionalismo ciudadano" que inteligentemente comporta una inequívoca elección por el gobierno del Derecho que emana de la Ley fundamental del Estado.

Segundo. La Constitución intenta subordinar a la totalidad de los andamios del Estado. Una de las garantías más fértiles para guardar la supremacía de la Ley fundamental es la del control de constitucionalidad. Un juicio de conformidad con el parámetro objetivado en la Ley fundamental.

Tercero. La inconstitucionalidad configura un problema complejo. Frente a la naturaleza genérica, abstracta, vaga e indeterminada de muchas previsiones contenidas en la lengua constituyente del Estado, un problema sobre la regularidad pareciera que podría admitir más de una respuesta con el estatus anunciado y propiciado. Queda descartado, pues, que exista una respuesta correcta para toda cuestión constitucional. Precisamente, por esas propiedades, fue elegida "la sentencia".

Cuarto. No es usual que las Constituciones dispongan en su textura el enjuiciamiento de la regularidad del proceso de reforma constitucional.

Quinto. La CPC 1991 insinúa, sin dudar, los "vicios de procedimiento" en el artículo 241 (incisos 1 y 2). Fuera del encaje dispuesto en el artículo 241, en sus incisos mencionados, no hay más competencia para conocer respecto de ningún otro vicio del proceso de reforma o vinculado con la convocatoria y realización de un referendo. Por las razones mencionadas, la doctrina de la sustitución de la Constitución, sin hacer mella de su valía o cotización científica, no resulta susceptible de ser guardada en la lengua de la CPC 1991, en tanto las piezas del citado dogma pretendan fulminar por inconstitucional o inexequible un vicio 
que no fuese de los catalogados en los incisos pertinentes del artículo 241. El órgano CCC carece, constitucionalmente, de una competencia explícita para cumplir el objetivo de aplicar la sofisticada doctrina de la sustitución. El Derecho de la Constitución es lo que dice la Ley fundamental. Si los jueces no actúan de conformidad con sus prescripciones, no se debería afirmar que ella dice lo que los jueces con sus sentencias dicen que es, sino que éstos no tienen razones tan valederas como verdaderas para sustentar sus juicios, cuya racionalidad viene exigida por el imperativo republicano de la forma de gobierno.

Sexto. Las cuestiones jurisdiccionales son políticas porque se relacionan con el sustento, la defensa o el desarrollo del orden jurídico; en particular, el enjuiciamiento del proceso de reforma, en sus aspectos formales. En efecto, al encontrarse en discusión la constitucionalidad de la variación, comporta un conflicto político. La CPC 1991 confirió a la CCC un rol destacadísimo en el proceso del constitucionalismo colombiano, y aquel órgano debe cumplir con sus resoluciones jurisdiccionales de acuerdo con el Derecho. Sin embargo, no se alcanzan a comprender los beneficios de privar a la ciudadanía de la posibilidad de expresar sus ideas en las urnas. Las elecciones de congresistas, las elecciones de asambleístas constituyentes, en fin, cualquier elección en la que intervengan los ciudadanos para votar a sus representantes políticos de modo directo es, sin dudas, "evidentemente superior como cuestión de democracia y de valores democráticos que las bases indirectas y limitadas"38 de la que dispondría la legitimación democrática del poder jurisdiccional del Estado (los jueces).

La CPC 1991 autorizó a la CCC para conocer sobre la existencia de un vicio en el procedimiento de formación, pero no le dio autoridad para configurar una nueva competencia. La CCC no dispone, constitucionalmente, de poder configurador de la Ley fundamental colombiana. Me pregunto si en "la sentencia",

38 WaLDRon, Jeremy: "El centro de la argumentación contra el control judicial de la legislación", ob. cit., p. 201. 
al impedirse el pronunciamiento de la ciudadanía, los magistrados que forjaron la "mayoría" de la CCC terminaron siendo más supremos que jueces.

Los jueces de la CCC que integraron la "mayoría", con buenas intenciones y quizá hasta sin proponérselo, prefirieron que el ciudadano haya de "asistir a su propia vida", pero consideraron "improcedente cualquier aspiración a vivirla" 39.

Séptimo. "La sentencia" produjo una contrarreforma por conducto jurisdiccional de la CCC no autorizada expresamente por la Ley fundamental de 1991.

Octavo. El discurso constitucional se origina en el poder constituyente. Por de pronto, ese elemento de tecnología social existe, porque fue creado. Luego, el campo de su realización continúa de este modo: ciudadanos, autoridades, ciudadanos y autoridades, entre estas últimas, los jueces. Los jueces no son los únicos ni principales realizadores en una comunidad abierta.

Noveno. La lengua constitucional instituye una norma para que cada individuo pueda pensar, desarrollar y mantener, con igual libertad, su propio y soberano plan existencial. Por eso, alentar una sociedad abierta de los realizadores del sistema constitucional estimula, sin dudas, el debate público. Éste, a su vez, pone de manifiesto la participación que, al mostrar signos de cohesión, puede inducir, razonablemente, la estabilidad jurídico-constitucional, es decir, una comunidad dispuesta a vivir, a regirse por reglas, antes que en descuido o inobservancia de ellas. Pensar de este modo no es una herejía ni una esperanza fútil. Constituye afirmar que se puede vivir dentro de las cuatro esquinas que determina la norma constitucional; quizá la eficacia o el cumplimiento más o menos acabado o totalizador del Derecho constitucional signifiquen, en el futuro, un experimento crucial, en el ámbito de la imperfección natural de toda obra humana.

39 Baricco, Alessandro: Seda, Barcelona, Anagrama, 2012, p. 11. 
El único camino para inaugurar y sostener una sociedad abierta puede recorrerse con la determinación y el cumplimiento de límites para ciudadanos y servidores públicos. Todo el aparato estatal, fundado por la Constitución, queda investido de limitaciones indisponibles que, en caso de ser transgredidas, harán colapsar la separación de funciones gubernativas y la subordinación del servidor público a la Constitución.

Los jueces, al ejercer sus poderes, deben conocer el asunto, subsumirlo y resolverlo dentro de los límites determinados para la desenvoltura de sus facultades gubernativas. Por caso, la discrecionalidad jurisdiccional, en el supuesto de los vicios en el procedimiento de formación de una reforma, mantiene un decidido ámbito en el artículo 241, incisos 1 y 2, de la CPC 1991. Cuando la jurisdicción actúa más allá de tal emplazamiento, independientemente de la plausibilidad de su comportamiento institucional, deberá ejercer un poder de disposición, ya sea para crear un ideal regulativo de su competencia, ya sea para dejar a un lado las normas aplicables; en cualquier supuesto, en liza con la separación de funciones gubernativas y en demérito de la fortaleza de su legitimación.

Décimo. El constitucionalismo ciudadano, un cultivo abnegado de la Ley fundamental, alumbra la factibilidad de una participación determinante e inclusiva de cada ser humano en la búsqueda y afirmación de una ciudadanía plena.

"La sentencia" significa un verdadero contrapeso, una especie de "gobierno de los jueces" demoledor e injustificado. Ella misma, con afán de constitucionalidad, negó y prohibió el instrumento racional y pacífico de reforma, el sufragio de los ciudadanos que integran el pueblo ${ }^{40}$, único presupuesto ontológico del Derecho constitucional. Contra la emergencia que produjo "la sentencia" ensayo esta tesis, cuyas proposiciones capitales se construyen y justifican, en todo el recorrido de este estudio, con las propias piezas de la Ley fundamental colombiana de 1991.

40 V. Carta de Thomas Jefferson a Spencer Roane. 6 de setiembre de 1819: https://founders. archives.gov/documents/Jefferson/98-01-02-0734 Consultado el 28/11/2018 